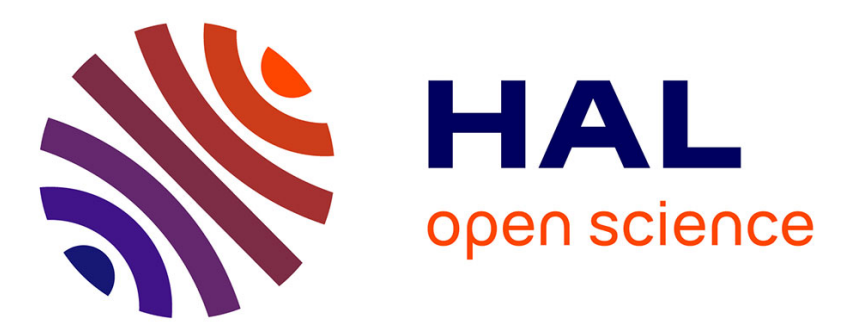

\title{
Study on self-loosening of bolted joints excited by dynamic axial load
}

\author{
J.H. Liu, H.J. Ouyang, Z.Q. Feng, Z.B. Cai, X.T. Liu, M.H. Zhu
}

\section{To cite this version:}

J.H. Liu, H.J. Ouyang, Z.Q. Feng, Z.B. Cai, X.T. Liu, et al.. Study on self-loosening of bolted joints excited by dynamic axial load. Tribology International, 2017, 115, pp.432-451. 10.1016/j.triboint.2017.05.037 . hal-02398144

HAL Id: hal-02398144

https://hal-univ-evry.archives-ouvertes.fr/hal-02398144

Submitted on 4 Jun 2021

HAL is a multi-disciplinary open access archive for the deposit and dissemination of scientific research documents, whether they are published or not. The documents may come from teaching and research institutions in France or abroad, or from public or private research centers.
L'archive ouverte pluridisciplinaire HAL, est destinée au dépôt et à la diffusion de documents scientifiques de niveau recherche, publiés ou non, émanant des établissements d'enseignement et de recherche français ou étrangers, des laboratoires publics ou privés.

\section{(c)(1)}

Distributed under a Creative Commons Attribution| 4.0 International License 


\title{
Study on self-loosening of bolted joints excited by dynamic axial load
}

\author{
Jianhua Liu ${ }^{1}$, Huajiang Ouyang ${ }^{2}$, Zhiqiang Feng ${ }^{3}$, Zhenbing Cai ${ }^{1}$, Xuetong Liu $^{1}$, Minhao Zhu ${ }^{1}{ }^{1}$ * \\ 1. Tribology Research Institute, Southwest Jiaotong University, Chengdu 610031, China \\ 2. School of Engineering, University of Liverpool, Liverpool L69 3GH, UK \\ 3. Université d'Évry-Val d'Essonne, LMEE, Évry, France
}

\begin{abstract}
Loosening tests of bolted joints are carried out under various preloads and excitation amplitudes. Three coatings are utilized to treat bolts, and their effects on the anti-loosening performance are studied. For the $\mathrm{MoS}_{2}$ coated bolt, a reasonable preload is calculated, and its anti-loosening performance is also examined. It is found that the anti-loosening performance of $\mathrm{MoS}_{2}$ coating on bolt is better than that of the other two coatings. Under the same equivalent stress as that of the uncoated bolt at the thread root, both the preload and the anti-loosening performance of the $\mathrm{MoS}_{2}$ coated bolt are significantly greater. Additionally, a FE model is created to simulate the bolted joint, and very good agreement is found between numerical and experimental results.
\end{abstract}

Key words: Bolted joints; Loosening; Fretting wear; Frictional energy dissipation

\section{Introduction}

Because of the advantages of simple structure, convenient use and low cost, bolted joints are widely used in many engineering structures. Self-loosening is one of the main failure modes of bolted joints in vibration environment, thus self-loosening mechanisms have been widely studied by many researchers, in view of their importance and complexity. Experimental results indicate that the common causes of self-loosening of bolted joints are plastic deformation of the fastener, slippage and fretting wear between the contact surfaces ${ }^{[1-8]}$. The FE method has been increasingly used to study the dynamic behaviour of bolted joints in the past two decades. In addition, a number of anti-loosening methods have been reported.

Goodier and Sweeney ${ }^{[1]}$ investigated the loosening mechanism of bolted joints excited by axial load, and suggested that a micro slippage occurred radially between the contact threads because of the change of axial load. Based on static tensile tests, they pointed out that the bolt twisted in the loosening direction during loading and twisted in the opposite direction during unloading, and thus loosening behaviour occurred at last. Hosokawa et al. ${ }^{[9]}$ found that due to the effect of Poisson's ratio, relative radial micro-slip between the contact threads occurred under axial load. The self-loosening mechanism of bolted joints was attributed to a reduction in friction, which led to slip both on the contact threads and on the bearing surfaces ${ }^{[2,10-19]}$. Bickford ${ }^{[14]}$ and Jiang et al. ${ }^{[2,}$ $\left.{ }^{15}, 16\right]$ described a loosening process of bolted joints: preload reduced first slowly because of some of the relaxation mechanisms, and then quickly. This was because sufficient preload was lost and the friction forces dropped below a critical level, which caused the nut to back off. Ibrahim et al. ${ }^{[17]}$ and Horn and Schmitt ${ }^{[18,19]}$ showed that fretting wear between contact surfaces, which caused the clamping force to decrease in the early stage, was one of the reasons for self-loosening of bolted joints. Some studies reported that fasteners could twist with or against gravity when threaded fasteners were subjected to axial harmonic excitation ${ }^{[20-24]}$. Hess and co-workers ${ }^{[21]}$

\footnotetext{
* Corresponding author. Tel: +86 028 87600715; fax: +86 02887600723

E-mail address: zhuminhao@swjtu.cn
} 
observed that the nut moved down along the bolt in a bolted joint system when subjected to a high frequency excitation, but moved up in the opposite condition at low frequency excitation. Nassar et al. ${ }^{[5,25]}$ and Yang et al. ${ }^{[3,26]}$ experimentally and numerically investigated the self-loosening behaviour of bolted joints excited by dynamic axial load. The results showed that the plastic deformation of the fastener was a major cause of self-loosening in bolted joints. Liu et al. ${ }^{[4]}$ experimentally found that preload reduced quickly due to the plastic deformation of the fastener, then slowly as a result of fretting wear between the contact threads. In summary, the common causes of self-loosening of bolted joints are plastic deformation of the fastener, slippage and fretting wear between contact surfaces.

Due to the complexity of the thread profile of bolted joints and the limitation of finite element software, axisymmetric finite element models or even two-dimensional models were often used to study the mechanical characteristics of bolted joints. Bahai et al. ${ }^{[27]}$ and Zhao ${ }^{[28]}$ used a two-dimensional model and an axisymmetric three-dimensional model to study the load distributions along the threads and the stress concentration factors at the thread roots. Alkatan et al. ${ }^{[29]}$ presented a two-dimensional model to calculate the stiffness of the bolt head, nut and the clamped plates. Based on the model of only one half of a bolted joint, Jiang et al. ${ }^{[16]}$ explored the self-loosening mechanism of a bolted joint under cyclic transverse loading, and Liu et al. ${ }^{\text {[30] }}$ studied the dynamic response of a bolted joint under dynamic shear displacement. Recently, helical thread models with tetrahedral elements were used by some researchers: Izumi et al. ${ }^{[1,32]}$ studied the self-loosening mechanism of a bolted joint subjected to shear loading, and Yokoyama et al. ${ }^{[33]}$ researched the self-loosening mechanism of a bolted joint subjected to torsional loading. In addition, external threads and bolt shank were modelled with hexahedral elements, and the bolt model was created by tying the external threads to the bolt shank. The nut model was similarly created using the same method ${ }^{[4,34,35]}$. An effective model, which can construct helical thread geometry, must be used to accurately capture the mechanical characteristics and self-loosening phenomena of bolted joints. Fukuoka et al. ${ }^{[36]}$ presented the mathematical expressions of thread cross section profile, and created an effective model to study the load distributions along the threads and the stress distributions at the thread roots. Yang et al. ${ }^{[37]}$ and Rafatpanah ${ }^{[38]}$ used the same method to create a FE model to investigate the mechanical behaviour of a bolted joint. There are three conventional methods to apply a bolt preload: a temperature increase is applied to one of the clamped members ${ }^{[15,16,39,40]}$; a preload is applied over the bolt cross-section ${ }^{[25,41-43]}$; and an initial interference between the bolt head and the upper surface of the clamped member is defined to simulate the application of the preload ${ }^{[32,44,45]}$. Unfortunately, these afore-mentioned three methods for applying a preload cannot simulate the friction torque applied to the bolt during the tightening process.

In the design of bolted joints, tensile stress acting on the cross section of fastener is not generally permitted to be beyond its yield strength. Consequently, the anti-loosening method is focused on preventing slippage between contact surfaces. Generally, safety-wires, coatings and inserts, thread-locking adhesive, and spring-washers are used to prevent loosening ${ }^{[46]}$. Housari et al. ${ }^{[6]}$ and Zaki et al. ${ }^{[8]}$ used experimental and theoretical methods to research the effect of the friction coefficients both on the contact threads and on the bearing surfaces on self-loosening of bolted joints excited by cyclic transverse loads. It was found that the loosening rate reduced with the increase of the friction coefficients both on the contact threads and on the bearing surfaces. Some researchers examined the loosening behaviour of locking nuts including nylon insert ${ }^{[47-49]}$. It was found that clamping force would no longer reduce after it dropped to a certain level. 
Cheatham et al. ${ }^{[50]}$ reported the loosening process of fasteners locking Heli-Coil inserts. They discovered that clamping force also remained at a steady-state value, which was smaller than the initial preload. Experiments by Takemasu et al. ${ }^{[1]}$ and analyses by Izumi et al. ${ }^{[32]}$ were carried out to investigate the anti-loosening performance of bolted joints with double nuts. Eccles et al. ${ }^{[52]}$ presented an experimental investigation of loosening of prevailing torque nuts. The results showed that repeated tightening of prevailing torque nuts could reduce its anti-loosening performance due to thread wear. Hess et al. ${ }^{[7]}$ conducted tests on the resistance to loosening of threaded fasteners with five different washer configurations. They stated that "the internal teeth lock washer on plain washer" provided the best anti-loosening performance. Sase et al. ${ }^{[53,54]}$ invented new bolts named step lock bolts (SLBs) and found that they had good anti-loosening characteristics.

In this paper, the self-loosening behaviour of bolted joints excited by dynamic axial load is studied at five levels of both preload and excitation amplitude. According to previous studies, PTFE coating and $\mathrm{MoS}_{2}$ coating have low coefficient of friction and good self-lubricating properties ${ }^{[55-59]}$, and TiN coating has high hardness and excellent wear-resistance ${ }^{[60-63]}$. Hence, the three coatings are utilized to treat bolts respectively, and their effects on anti-loosening performance of bolted joints are investigated in this paper. An accurate FE model is built up to simulate a bolted joint. Based on the finite element model, preload is applied by twisting the head of the bolt, and the tightening process is realistically simulated. A theoretical method is firstly used to validate the effectiveness of the FE model. The cumulative plastic deformation caused by axial excitation, frictional stress, relative slippage and dissipated frictional energy per unit area are studied for varying parameters (preload, amplitude of axial excitation and friction coefficient). In addition, the clamping force loss caused by the plastic deformation and the slip between the threads is analysed in the first three loading cycles.

\section{Experimental method}

Fig. 1 shows the testing equipment used in the experiments. The bolt testing fixtures are made of steel which has a high fatigue strength. To measure the clamping force of bolted joints, a load cell is inserted between the fixtures. The test process and the testing equipment are described as follows:

(1) Fix the end of the lower fixture on the test platform, and then assemble the upper fixture, the load cell and the lower fixture using a bolt and a nut.

(2) Place the two locating pins into the holes, and then apply a certain torque to the bolted joint using a digital electronic torque wrench, which brings the preload of the bolted joint to reach a set value.

(3) Take out the locating pins, and then apply an axial excitation to the end of the upper fixture.

\subsection{Preload selection}

According to Handbook of Mechanical Design ${ }^{[64]}$, for the bolt made of carbon steel, the recommended tensile stress on the section of bolt shank caused by preload is from the sixty to seventy percent of the yield strength of bolt material. So the recommended preload is given by

$$
P_{0}=(0.6 \sim 0.7) \sigma_{\mathrm{s}} A_{\mathrm{s}}
$$

where $A_{\mathrm{s}}$, the valid cross section, is defined as

$$
A_{\mathrm{s}}=\frac{\pi}{4}\left(\frac{d_{1}+d_{2}}{2}-\frac{\sqrt{3} P}{24}\right)^{2}
$$

Here, $d_{1}$, defined as the thread minor diameter, is $10.106 \mathrm{~mm}, d_{2}$, defined as the basic pitch 
diameter of the thread, is $10.863 \mathrm{~mm}$, and $P$, defined as the pitch of the thread, is $1.75 \mathrm{~mm}$. Taking them into Eq. (2), and the valid cross section is determined as

$$
A_{\mathrm{s}}=84.3 \mathrm{~mm}^{2}
$$

In this study, the bolts and nuts are made of 1045 steel with yield strength of $325 \mathrm{MPa}$. Taking them into Eq. (1), the recommended preload is determined and it ranges from $16.4 \mathrm{kN}$ to $19.2 \mathrm{kN}$. Consequently, the preload of $18 \mathrm{kN}$ is firstly selected in the experiments. In practice, torque wrenches are commonly used to apply preload. Considering that the error of torque wrenches can reach $\pm 20 \%$, the preloads of $15 \mathrm{kN}$ and $21 \mathrm{kN}$ are selected. In order to better study the effect of preload on the self-loosening behaviour of bolted joints, interpolation of above three levels of preload has been conducted, and the preloads of $16.5 \mathrm{kN}$ and $19.5 \mathrm{kN}$ are also selected.

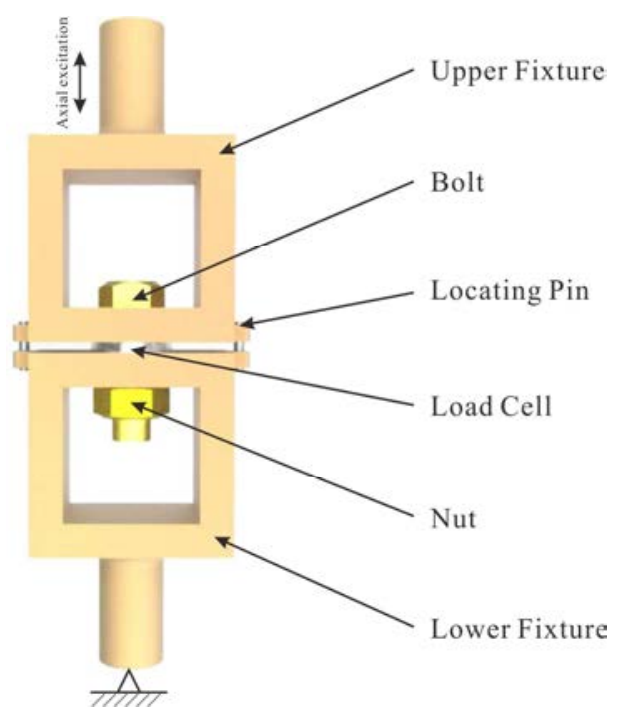

Fig. 1. Experimental setup

\subsection{Excitation amplitude selection}

The separation between the connected parts may occur in extreme environment, and it has a serious effect on the reliability of bolted joints. Some researchers have already conducted a number of related studies ${ }^{[26]}$. In this study, the numerical results show that under the preload of 18 $\mathrm{kN}$, one of the connected parts is separated from its adjacent part when the axial excitation, $F_{\mathrm{e}}$ $\left(F_{\mathrm{e}}=A_{\mathrm{F}}-A_{\mathrm{F}} \cdot \cos (60 \pi t)\right)$, reaches $18.5 \mathrm{kN}$, and the clamp force drops to zero. The axial excitation amplitude, denoted as $A_{\mathrm{F}}$, is $9.25 \mathrm{kN}$ in this condition, so the amplitude of $10 \mathrm{kN}$ is firstly selected in the experiments. In order to study the effect of excitation amplitude on the self-loosening behaviour of bolted joints, two levels of excitation amplitude are respectively selected which are larger and smaller than this first selection. In addition, all experiments are conducted at a frequency of $30 \mathrm{~Hz}$ in air at room temperature.

\subsection{Preparation of coating}

PTFE coating and $\mathrm{MoS}_{2}$ coating are applied by means of spraying. The fine PTFE powders (or $\mathrm{MoS}_{2}$ powders) are uniformly dispersed in adhesive of epoxy. After descaling, de-rusting and sand blasting, the mixture is sprayed onto the surfaces of fasteners by a spray gun. Then the coating is solidified by heat curing at $200{ }^{\circ} \mathrm{C}$ for 1 hour. The thickness of the two coatings is $10 \pm 1 \mu \mathrm{m}$, and the micro-hardness of the PTFE coating and the $\mathrm{MoS}_{2}$ coating are $23 \pm 2 \mathrm{HV}$ and $60 \pm 5 \mathrm{HV}$. The TiN coating, with thickness of $5 \pm 1 \mu \mathrm{m}$ and hardness of $2500 \pm 50 \mathrm{HV}$, is deposited on the fasteners 
by an ion-plating equipment (MIP-800) at a bias voltage of $-100 \mathrm{~V}$ to $-150 \mathrm{~V}$ and a current of 350 A and a mixed gas $\left(\mathrm{N}_{2}+\mathrm{He}\right)$ pressure of $0.6 \mathrm{~Pa}$.

In order to reduce the dispersion of preload and loosening values, all bolts and nuts are cleaned in alcohol using an ultrasonic cleaner, and the test is repeated for five separate times under each experimental condition. After the tests, the thread damage is analysed by optical microscope, scanning electron microscope (SEM), energy dispersive x-ray system (EDS) and electron probe micro-analysis (EPMA).

\section{Experimental results}

\subsection{Effects on self-loosening}

\subsubsection{Effect of preload}

In order to analyse damage characteristics of the threaded bolts, the first three threads near the bearing surfaces of bolts are examined using an optical microscope. Fig. 2 shows the damage morphologies of the first three thread surfaces at varying preloads. If no adjustment is made for the damage morphologies in this paper, the right most thread is the first thread. Damage is not continuous and it is serious near the thread crests. The damage of the thread surface gets slight for threads further away, and it also gets slight with the increase of preload. It is because the contact stress is large under high preload, which makes relative slip both on the threads and on the bearing surfaces difficult to occur so that most of the contact area experiences sticking.

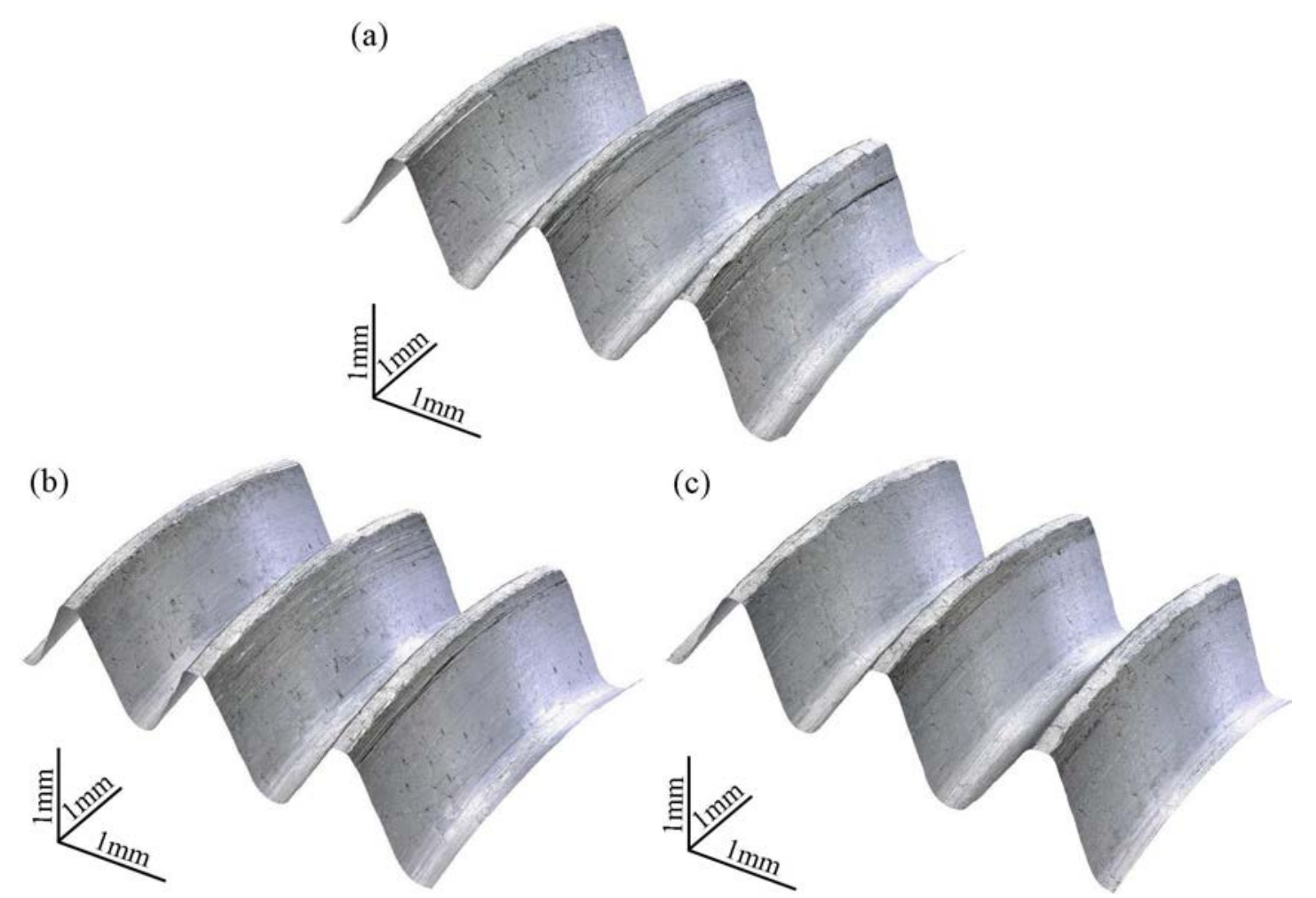

Fig. 2. OM morphologies of the first three thread surfaces at varying preloads $\left(A_{\mathrm{F}}=10 \mathrm{kN}\right)$ :

(a) $P_{0}=15 \mathrm{kN}$; (b) $P_{0}=18 \mathrm{kN}$; (c) $P_{0}=21 \mathrm{kN}$ 
As shown previously, the damage of the first thread is most serious, so it is analysed using SEM and EPMA/EDS in the subsequent experiments. Fig. 3 shows the wear micrographs and EPMA analyses of the first damaged thread surface. Ploughing with plastic flow occurs near the thread crest, and delamination phenomenon occurs near the root of the thread. The cause of the delamination phenomenon may be scratch between the contact threads when preload is applied, or cutting during the machining process. Delamination is the main damage phenomenon in the I area. In addition, the damaged surface shows delamination, pitting wear, and obvious plastic flow phenomenon in this area. Consequently, the main mechanisms are delamination and adhesive wear. In order to determine whether there is oxidation wear, EPMA is used to test the content of oxygen in the area denoted by $i$ and ii, which are each $40 \times 40 \mu \mathrm{m}$ in the damaged area. As shown in Fig. 3 (b), the content of oxygen is very low, so there is no oxidation wear in the $i$ area and the ii area (Fig. 3(c)). In summary, adhesive wear and delamination are the main wear mechanisms in this loading condition.
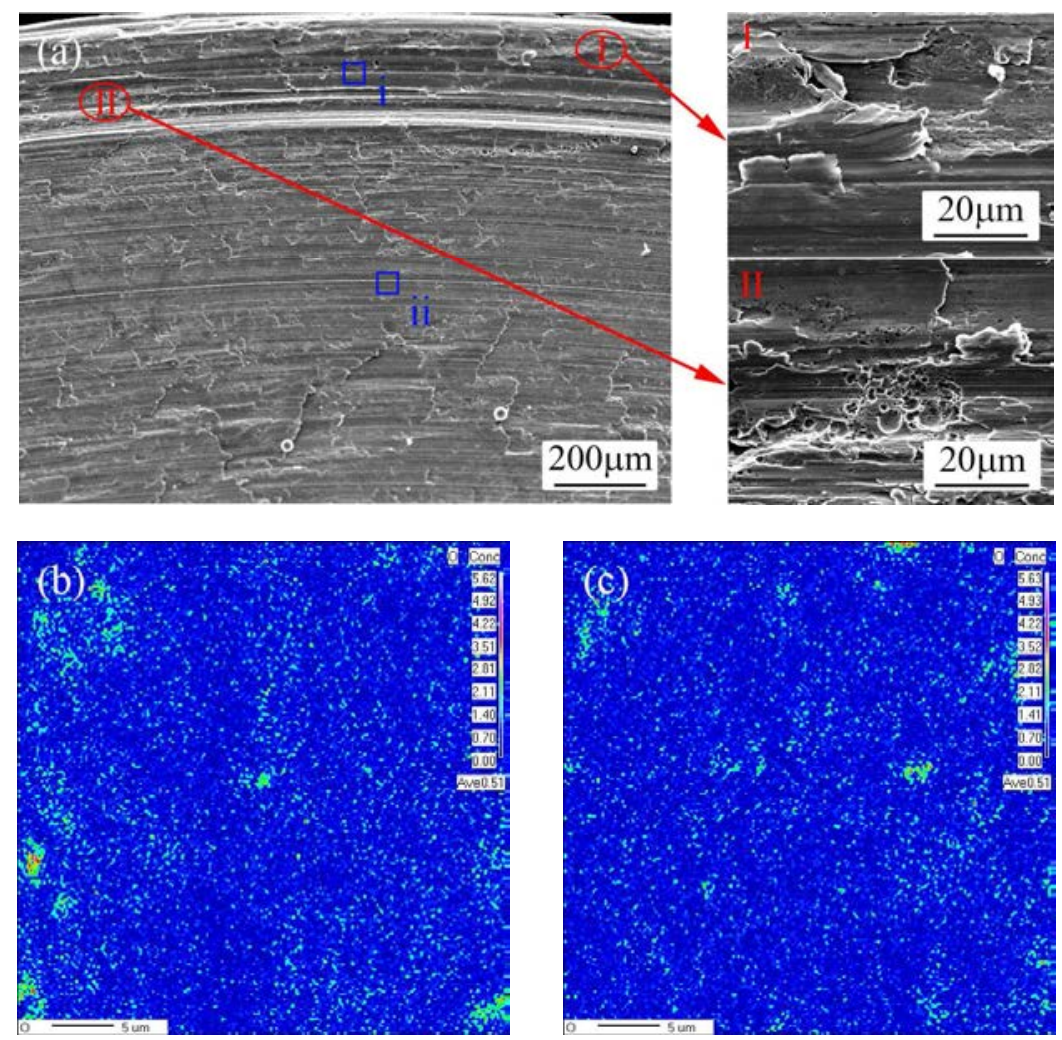

Fig. 3. SEM images and EPMA analyses of the first thread surface $\left(P_{0}=18 \mathrm{kN}, A_{\mathrm{F}}=10 \mathrm{kN}\right)$ : (a) SEM images; (b) EPMA analyses of the damaged area denoted as i; (c) EPMA analyses of the damaged area denoted as ii

Fig. 4 shows the wear micrographs of the first thread surface for the preload of $15 \mathrm{kN}$ and 21 kN. As shown in Fig. 4(a), ploughing with obvious plastic flow occurs in the damaged area near the crest of the thread. Moreover, delamination phenomenon occurs at the edge of the damaged area with ploughing phenomenon. As shown in Fig. 4(b), the damage of the first thread surface for the preload of $21 \mathrm{kN}$ gets slighter than that for the preload of $15 \mathrm{kN}$, and delamination phenomenon occurs at the crest of the thread. Compared with Fig. 3(a), with the increase of the preload, the damage is reduced gradually. Additionally, adhesive wear and delamination are the main wear mechanisms in those three conditions. 

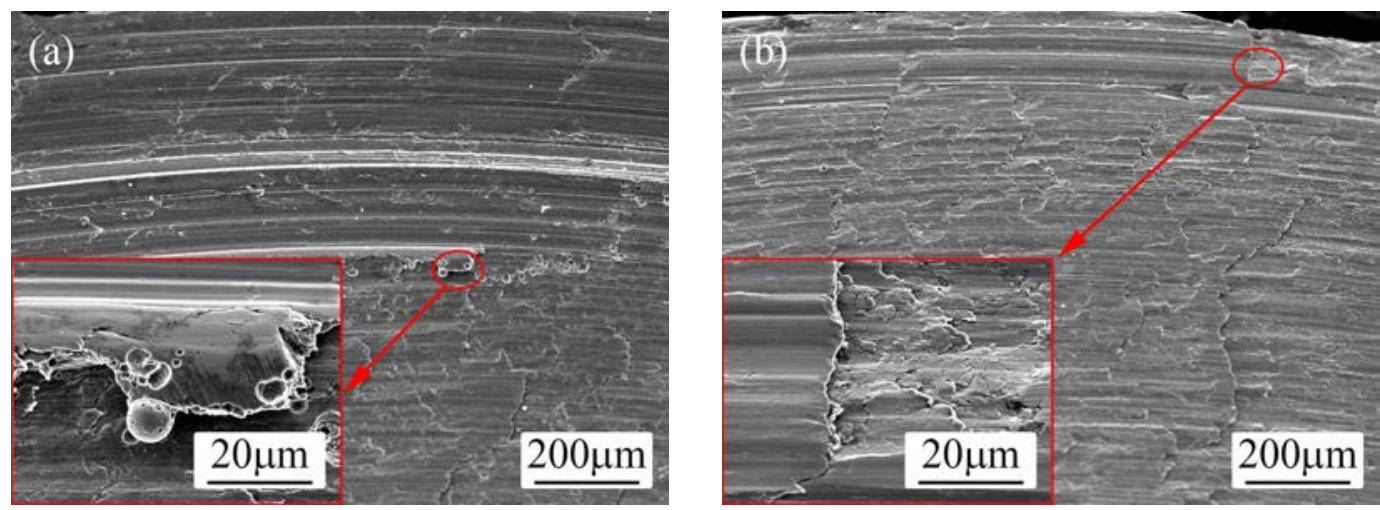

Fig. 4. SEM images of the first thread surface at varying preloads $\left(A_{\mathrm{F}}=10 \mathrm{kN}\right)$ :

(a) $P_{0}=15 \mathrm{kN}$; (b) $P_{0}=21 \mathrm{kN}$

Fig. 5 (a) shows reductions of torque and clamping force at three levels of the preload after $10^{6}$ loading cycles. Function $R_{\mathrm{T}}\left(10^{6}\right)$ is defined as the percentage of the breakaway torque necessary to loosen the tightening torque, and function $R_{\mathrm{F}}\left(10^{6}\right)$ is defined as the percentage of clamping force to preload. The reductions of torques and clamping forces become small with increasing preload. In addition, the value of $R_{\mathrm{T}}\left(10^{6}\right)$ is not equal to that of $R_{\mathrm{F}}\left(10^{6}\right)$. Compared with the tightening torque, the breakaway torque is usually smaller even if no dynamic load is applied to the bolted joints ${ }^{[65]}$, so in fact the value of $R_{\mathrm{T}}(0)$, defined as the percentage of the breakaway torque necessary to loosen the bolt to the tightening torque without axial excitation, is less than 1. This is one of the reasons why the value of $R_{\mathrm{T}}\left(10^{6}\right)$ is usually smaller than that of $R_{\mathrm{F}}\left(10^{6}\right)$. While the preload is $15 \mathrm{kN}, R_{\mathrm{T}}\left(10^{6}\right)$ is larger than $R_{\mathrm{F}}\left(10^{6}\right)$. This is because discontinuous pits are produced by fretting wear on the contact threads, and thus breakaway torque becomes large. Under high preload, most of the asperities on the surface deform plastically, diminish in size, or are even removed during the tightening process, and the real contact area is large, so plastic deformation of asperities caused by axial excitation is small. Consequently, under high preload, the clamping force decreases slowly in the initial period (See Fig. 5(b)). As discussed before, the damage of threads is slight under high preload, which causes the change in clamping force to be small. In summary, the bolted joint is not prone to loosening under high preload because of the slight damage and the small plastic deformation of asperities caused by axial excitation.
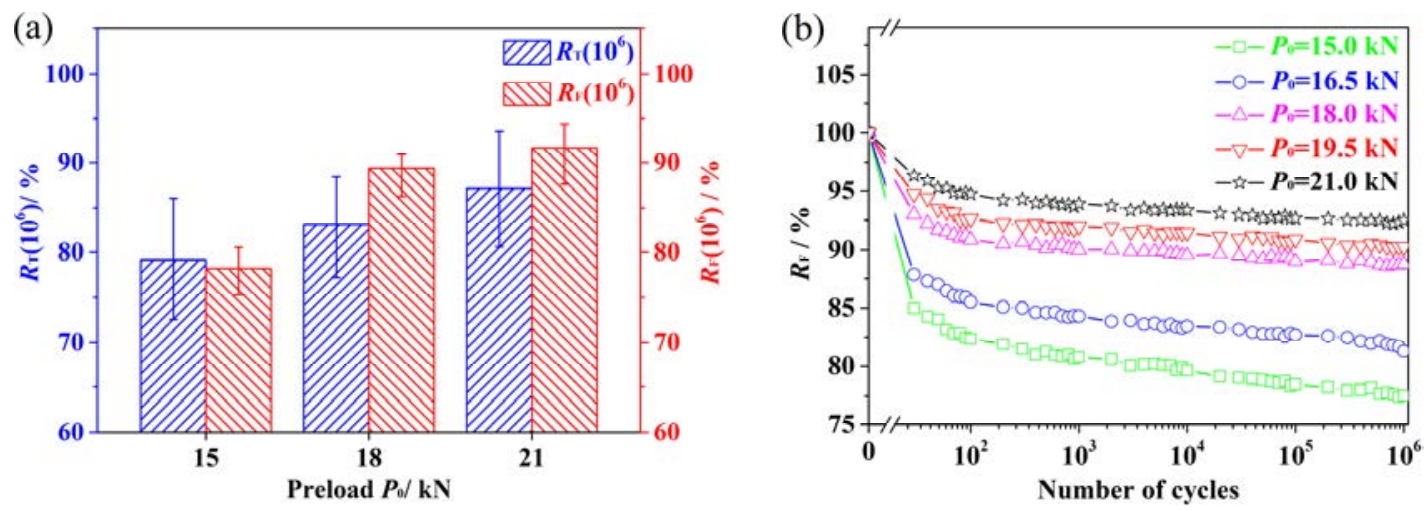

Fig. 5. Reductions of torque and clamping force and self-loosening curves at different preloads $\left(A_{\mathrm{F}}=10 \mathrm{kN}\right)$ : (a) Reductions of torque and clamping force; (b) Self-loosening curves 


\subsubsection{Effect of excitation amplitude}

As shown in Fig. 6, damage is not continuous and the damage is serious near the thread crests. The damage of the first thread surface is most serious. Because the contact stress and slippage between the contact threads increase as the excitation amplitude increases, the thread damage gets serious gradually. Fig. 7 shows the wear micrographs of the first thread surface at two levels of excitation amplitude. As can be seen from Fig. 7(a), the damage of the thread surface is very slight with ploughing and delamination phenomena. This shows that the main wear mechanism is abrasive wear, accompanied by adhesive wear and delamination. As shown in Fig. 7(b), the damaged surface exhibits ploughing and delamination phenomena at the crest of the thread. Therefore, delamination and adhesive wear are the main wear mechanisms. Compared with Fig. 3(a), with the increasing excitation amplitude, the main wear mechanism transforms from abrasive wear to delamination and adhesive wear.
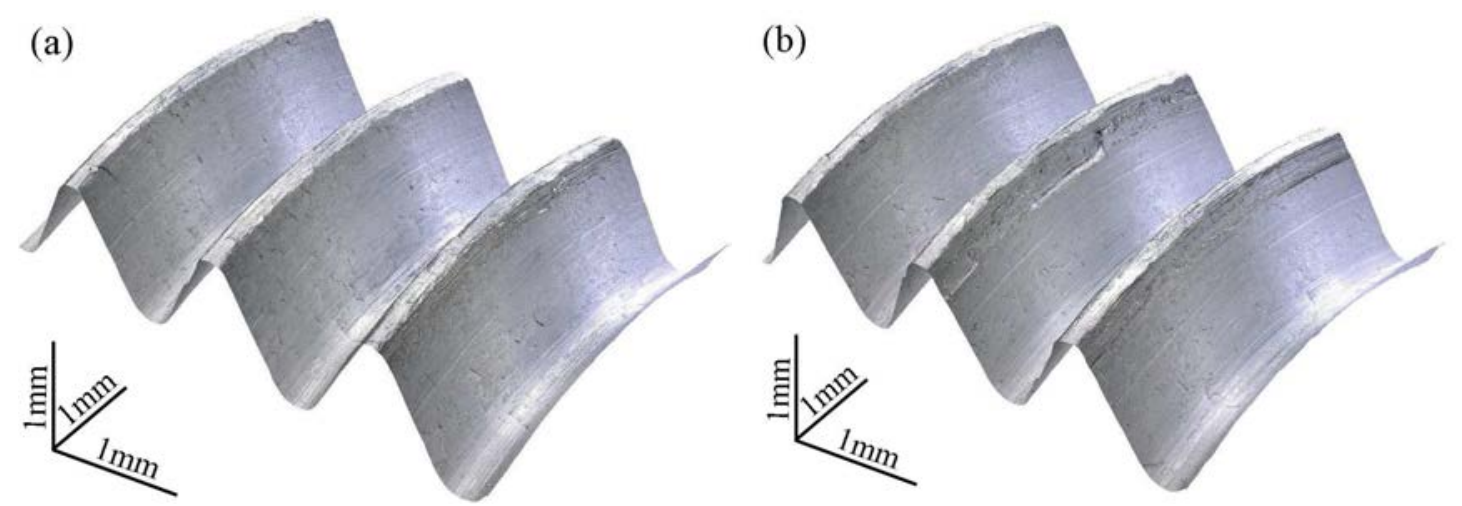

Fig. 6. OM morphologies of the first three thread surfaces at two levels of excitation amplitude

$$
\left(P_{0}=18 \mathrm{kN}\right) \text { : (a) } A_{\mathrm{F}}=7.5 \mathrm{kN} \text {; (b) } A_{\mathrm{F}}=12.5 \mathrm{kN}
$$
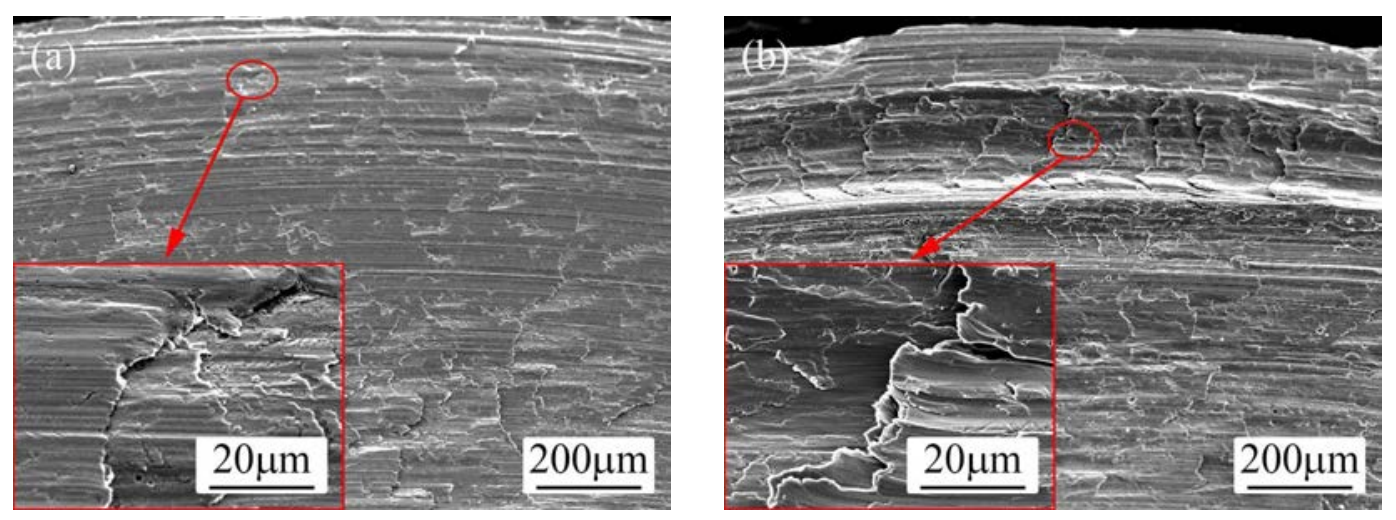

Fig. 7. SEM images of the first thread surface at two levels of excitation amplitude $\left(P_{0}=18 \mathrm{kN}\right)$ :

(a) $A_{\mathrm{F}}=7.5 \mathrm{kN}$; (b) $A_{\mathrm{F}}=12.5 \mathrm{kN}$

Fig. 8 (a) shows the reductions of torque and clamping force after $10^{6}$ loading cycles. Under higher excitation amplitude, clamping force drops more quickly under the same preload. While the reduction of tightening torque increases firstly and then decreases, it is probably because the bolt threads get a good grip caused by the serious discontinuous damage when the excitation amplitude is $12.5 \mathrm{kN}$. As shown in Fig. 8(b). Under the same preload, plastic deformation of asperities caused by axial excitation is large under high excitation amplitude, which causes the reduction in the clamping force to increase. Coupled with the serious damage, the bolted joint is prone to loosen under high excitation amplitude. 

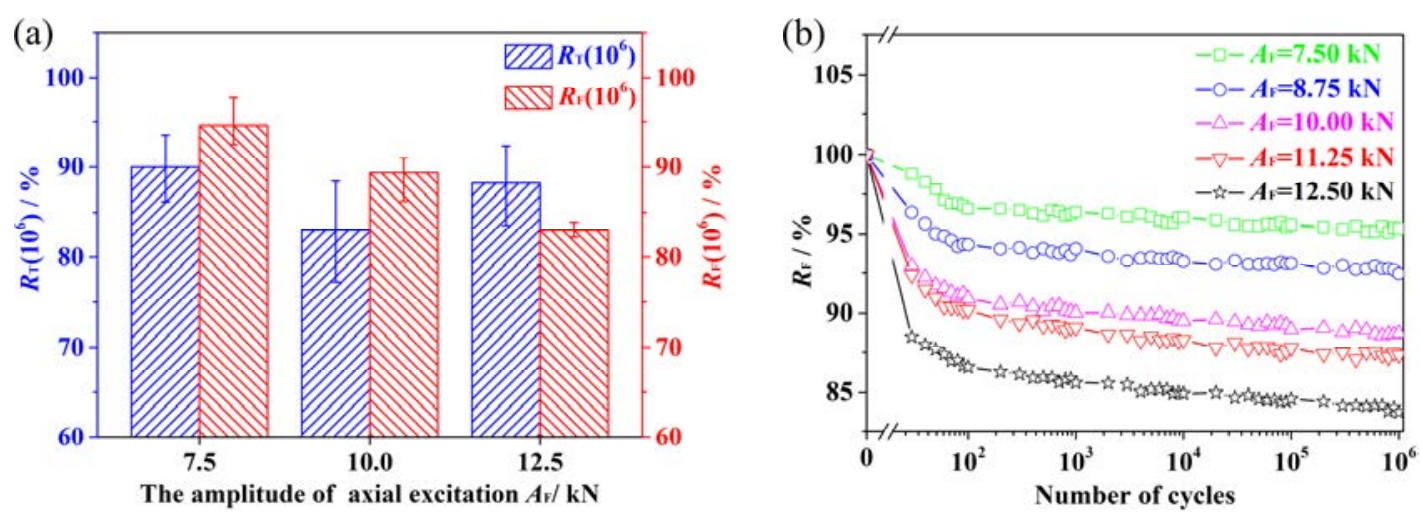

Fig. 8. Reductions of torque and clamping force and self-loosening curves at varying excitation amplitudes $\left(A_{\mathrm{F}}=10 \mathrm{kN}\right)$ : (a) Reductions of torque and clamping force; (b) Self-loosening curves

\subsection{Effects of three coatings on the anti-loosening performance}

\subsubsection{SEM investigation}

As stated earlier, the bolts tested in the above experiments are not coated. The bolts are coated with three different coatings in the following experiments, and the damage of thread surfaces and the change in clamping force are studied. Fig. 9 shows the damage morphologies of the first three thread surfaces for different coatings. As discussed earlier, damage is not continuous and it is serious near the crests of threads. The damage of PTFE coated threads is very serious, and that of $\mathrm{MoS}_{2}$ coated threads is slight. For the damage of TiN coated threads, extensive plastic deformation occurs at the crests of the threads because of the high friction coefficient of the contact threads ${ }^{[66]}$. It is found that the breakaway torque necessary to loosen a bolt is very large, and the bolts are severely damaged and even fracture in the experiments.

For the PTFE coated bolt, the SEM images and EDS analyses of the first thread surface are shown in Fig. 10. As can be seen from SEM images, the PTFE coating is removed from the substrate by the delamination in a local area, and the damage of the substrate is very slight. This is because bonding strength between PTFE coating and bolt matrix is low and the coating is easily removed, and then the detached coatings have an effect of solid lubrication. In addition, the surface of the substrate is characterized with pore shape. This may be because oxidation reaction takes place on the thread surface before PTFE coating is utilized to treat bolts. In addition, it is found from the EDS analyses that PTFE coating has been completely removed, because there are only iron, carbon and small amount of oxygen without fluorin in the region. Consequently, delamination is the main wear mechanism. For the $\mathrm{MoS}_{2}$ coated bolt, the SEM images and EDS analyses of the first thread surface are shown in Fig. 11. There appear many solid particles on the thread, and delamination and ploughing are the main wear phenomena. Because $\mathrm{MoS}_{2}$ particles have a self-lubricating property, the damage of the coating is slight. Likewise, the results of EDS analyses show that the $\mathrm{MoS}_{2}$ coating has been completely removed in a local area. Therefore, abrasive wear and delamination are the main wear mechanisms. For the TiN coated bolt, the SEM images and EDS analyses of the first thread surface are shown in Fig. 12. Because of the high friction coefficients between the contact surfaces, relative slip is not easy to occur on the contact threads or on the bearing surfaces. In addition, TiN coating has excellent wear resistance, and the damage of the coating is slight. Because of the high friction coefficient, the tightening torque is very large, and then plastic deformation occurs at the crests of the threads in the disassembling process of the bolted joints. Therefore, abrasive wear is the main wear mechanism. 

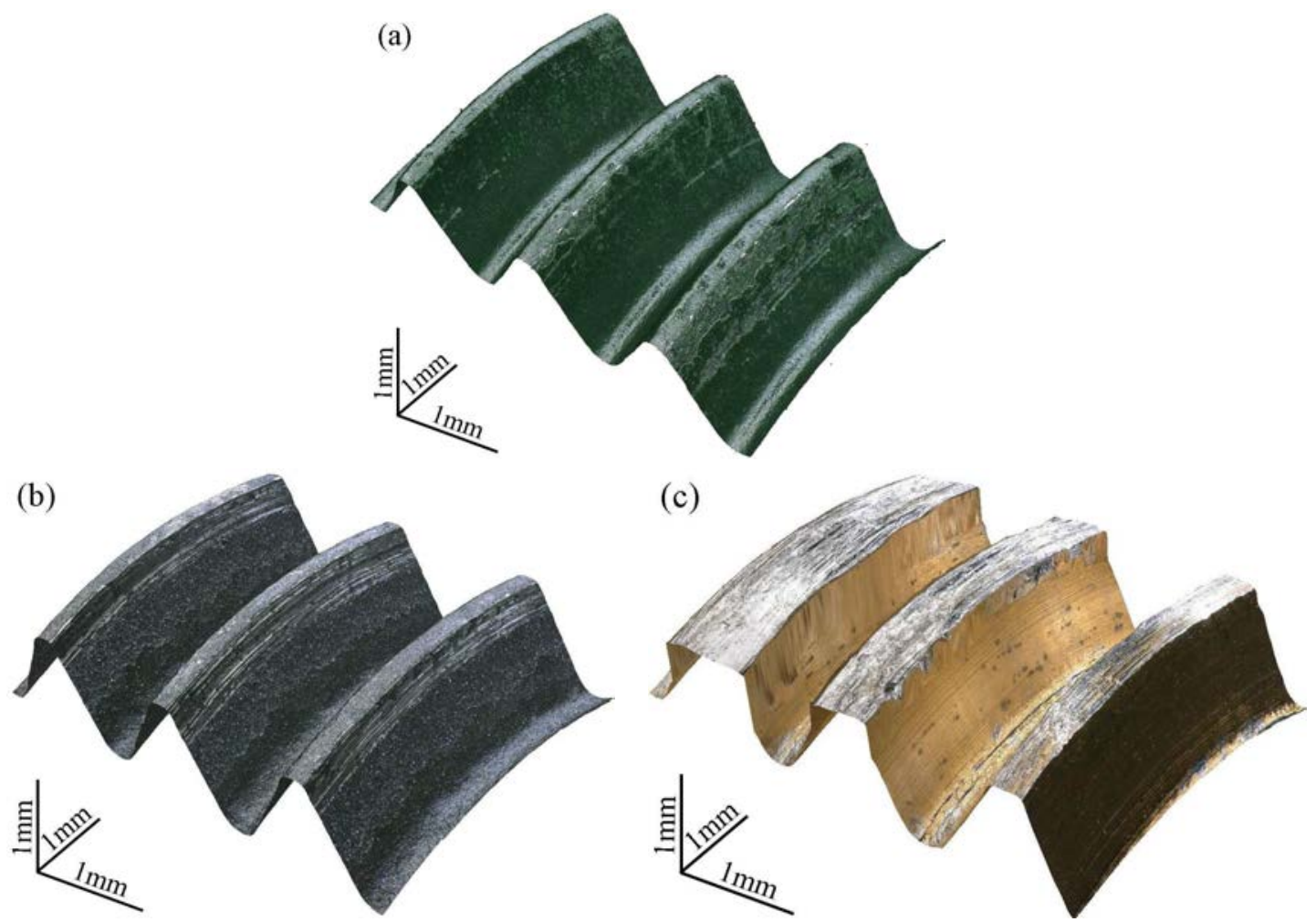

Fig. 9. OM morphologies of the first three thread surfaces for different coatings $\left(P_{0}=18 \mathrm{kN}, A_{\mathrm{F}}=10 \mathrm{kN}\right.$ ): (a) PTFE coating; (b) $\mathrm{MoS}_{2}$ coating; (c) TiN coating
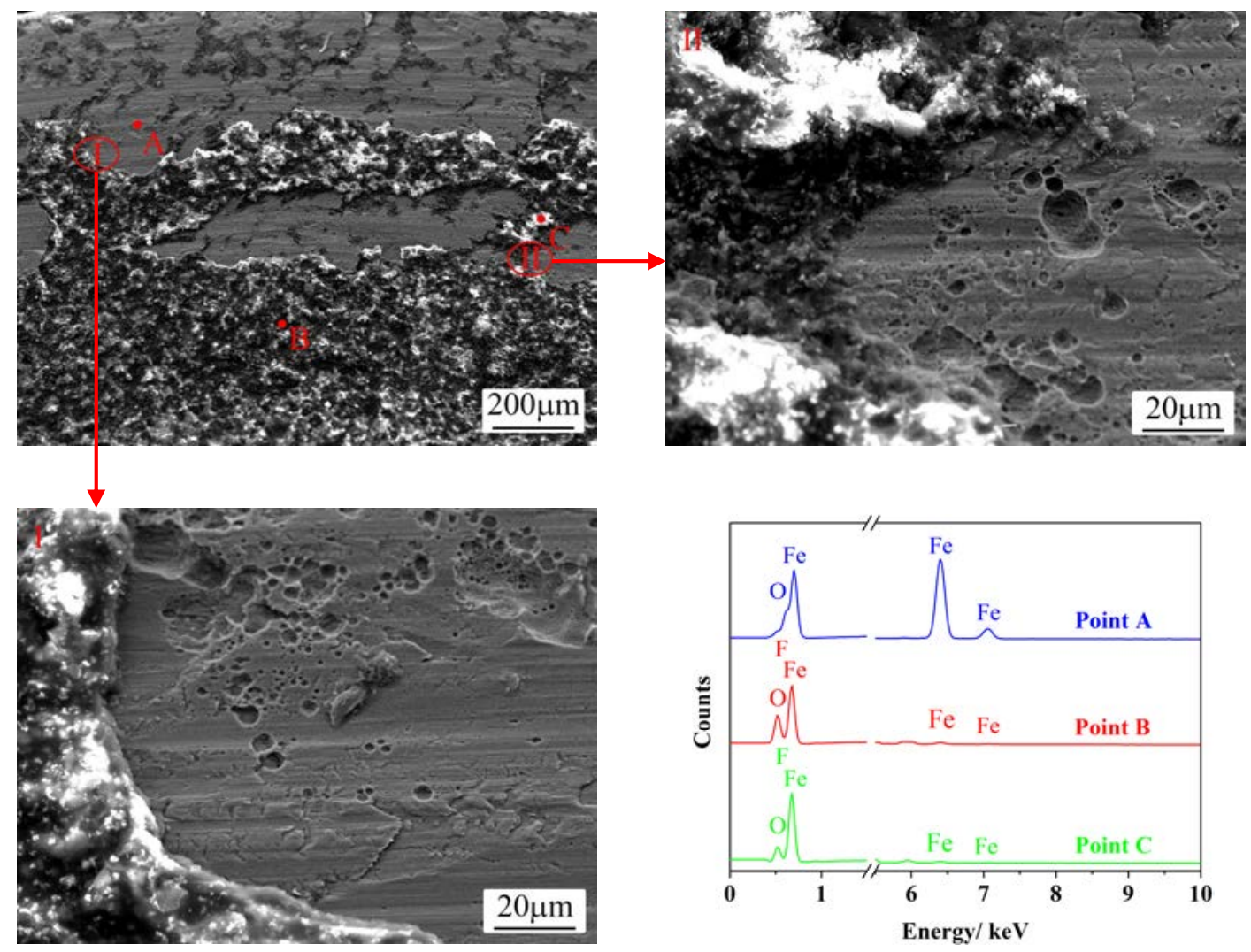

Fig. 10. SEM images and EDS analyses of the first thread surface of the PTFE coated bolt $\left(P_{0}=18 \mathrm{kN}, A_{\mathrm{F}}=10 \mathrm{kN}\right)$ 


\section{ACCEPTED MANUSCRIPT}

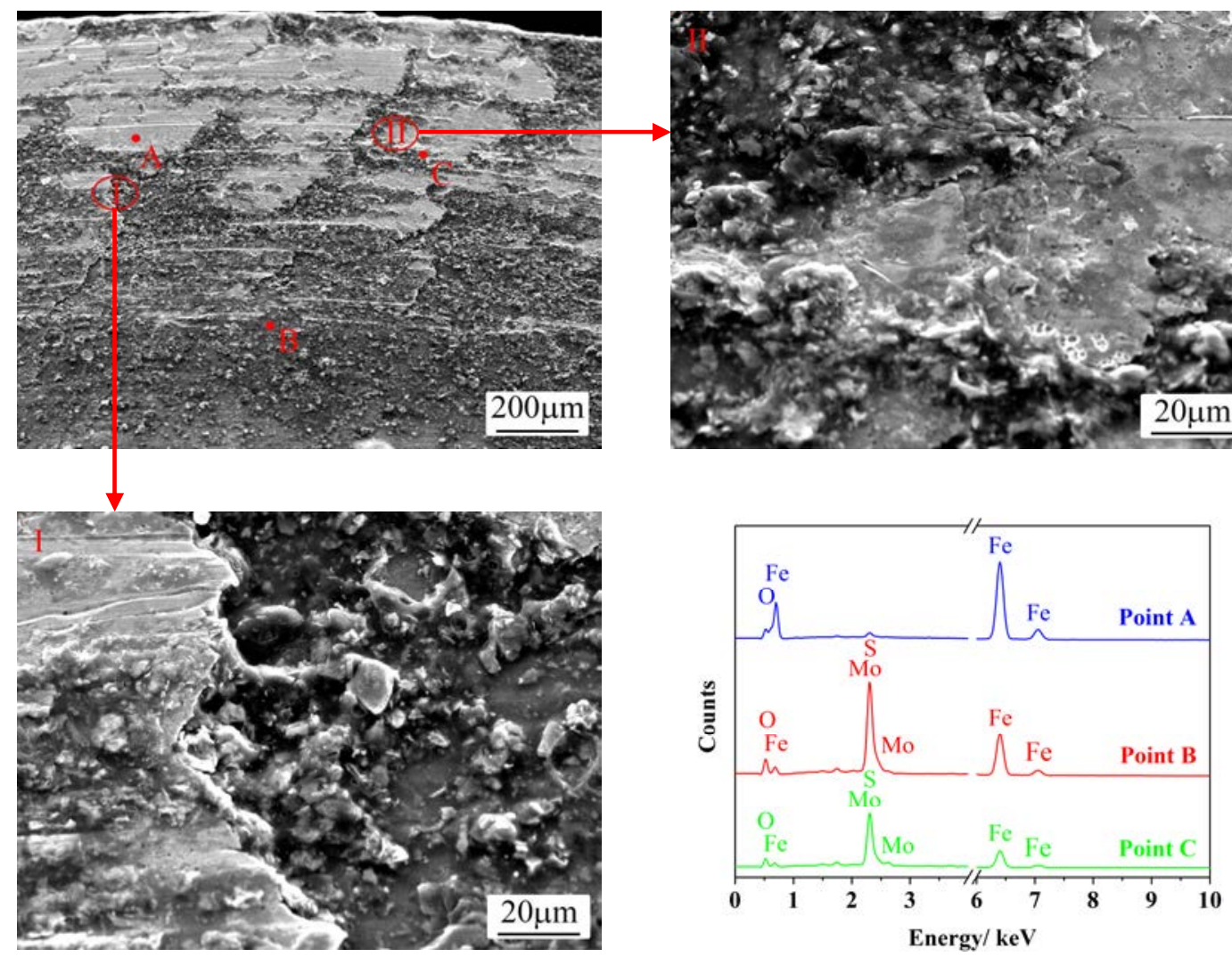

Fig. 11. SEM images and EDS analyses of the first thread surface for the $\mathrm{MoS}_{2}$ coated bolt $\left(P_{0}=18 \mathrm{kN}, A_{\mathrm{F}}=10 \mathrm{kN}\right)$

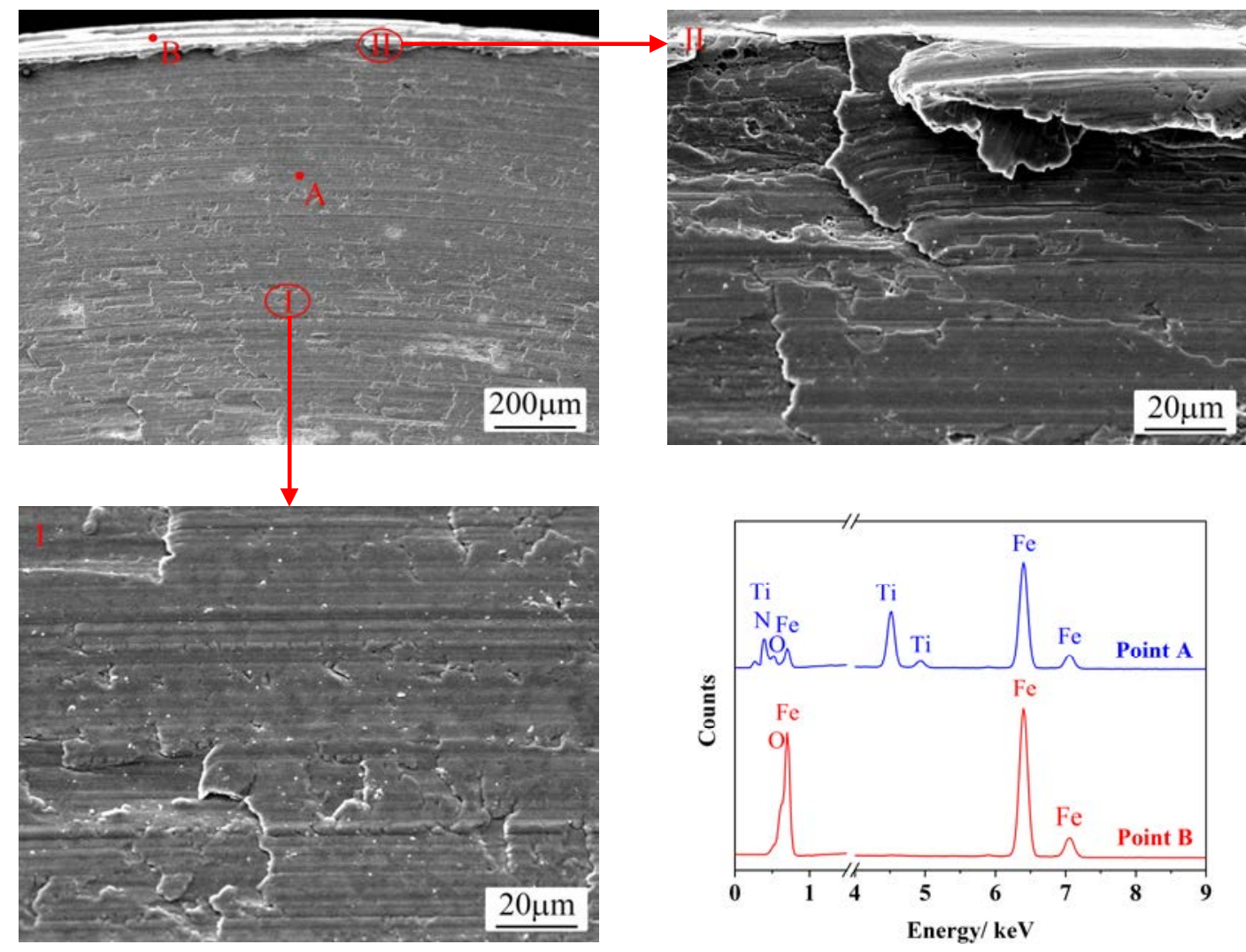

Fig. 12. SEM images and EDS analyses of the first thread surface for the TiN coated bolt $\left(P_{0}=18 \mathrm{kN}, A_{\mathrm{F}}=10 \mathrm{kN}\right)$ 


\subsubsection{Self-loosening curve}

Stage $\mathrm{I}$ is defined as the first 1000 cycles of the experiment, and the following cycles are referred to as Stage II. As can be seen from Fig. 13, $\mathrm{MoS}_{2}$ coating has the best anti-loosening performance, PTFE coating is acceptable, while TiN coating is the worst. As discussed before, plastic deformation of asperities and fretting wear are the main reasons of reduction in clamping force of bolted joints under axial excitation ${ }^{[4]}$. For the PTFE/MoS 2 coated bolts, there are not many large asperities on the thread surface, and the change in clamping force is less than that for the uncoated bolt in the initial stage of the experiment (denoted as Stage I). In comparison, because a large number of asperities deform plastically, diminish in size, or are even removed in Stage I, the change in clamping force for the TiN coated bolt is largest. As seen earlier, bonding strength between PTFE coating and bolt matrix is low and the damage of coating surface is serious, so the change in clamping force for the PTFE coated bolt is very large in Stage II. Because of self-lubrication and high bonding strength, the damage of the coating is slight, and the change in clamping force for the $\mathrm{MoS}_{2}$ coated bolt is smaller than that for the PTFE coated bolt in Stage II. Due to the excellent wear resistance and high bonding strength, the damage of the coating is slightest and the change in clamping force for the TiN coated bolt is smallest in Stage II.
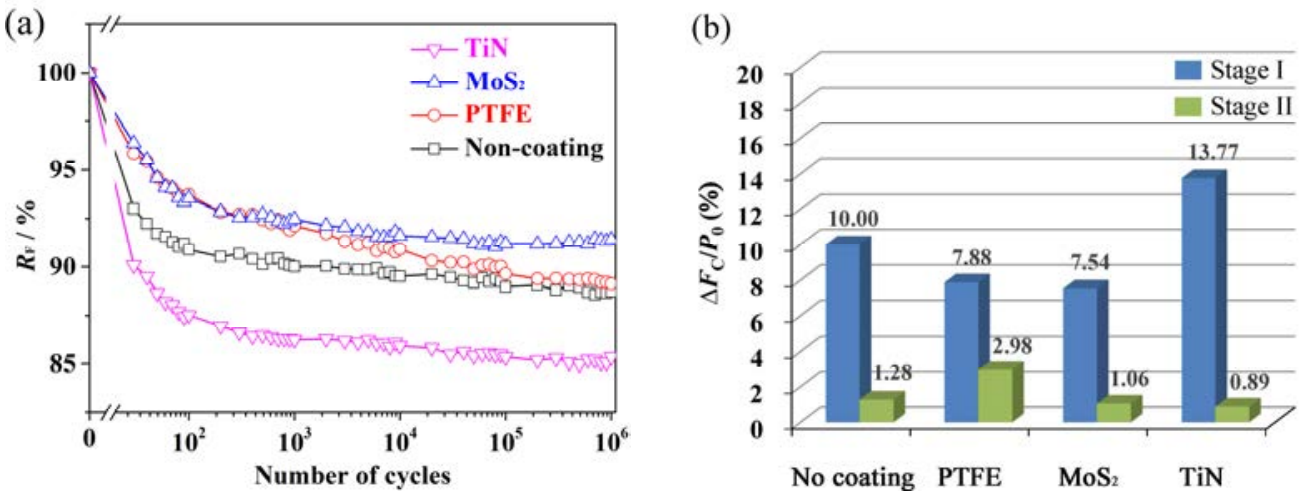

Fig. 13. Self-loosening curves and reductions of clamping forces for the three types of the coated bolts $\left(P_{0}=18 \mathrm{kN}, A_{\mathrm{F}}=10 \mathrm{kN}\right)$ : (a) Self-loosening curves; (b) Reductions of clamping forces

\subsection{Preload selection}

During the process of applying tightening torque, shear stress is generated by the friction torque on the section of the bolt shank. In practice, considering the presence of shear stress, the tensile stress caused by the preload is usually restricted to be smaller than eighty percent of the yield strength of the bolt material. For the $\mathrm{MoS}_{2}$ coated bolt, the friction coefficients both on the threads and the bearing surfaces is small. The friction torque is smaller than that for the uncoated bolt, which causes the shear stress to be smaller. Consequently, under the same equivalent stress as that of the uncoated bolt at the thread root, the preload can be appropriately increased.

The equivalent stress at the thread root is given by

$$
\sigma_{\mathrm{e}}=\sqrt{\sigma_{\mathrm{a}}^{2}+3 \tau_{\mathrm{t}}^{2}}
$$

where $\sigma_{\mathrm{a}}$ is the tensile stress caused by the preload, and $\tau_{\mathrm{t}}$ is the shear stress caused by the friction torque. The tensile stress at the thread root can be written as

$$
\sigma_{\mathrm{a}}=\frac{4 P_{0}}{\pi d_{1}^{2}}
$$


Here $d_{1}$ is the minor diameter of the thread.

In addition, the shear stress at thread root is expressed by

$$
\tau_{\mathrm{t}}=\frac{M_{\mathrm{t}} d_{1}}{2 I_{\mathrm{p}}}=\frac{8 P_{0}\left(\frac{d_{2}}{\cos \alpha} \mu_{\mathrm{t}}+\frac{P}{\pi}\right)}{\pi d_{1}^{3}}
$$

Here, $M_{\mathrm{t}}$ is the friction torque applied to the contact threads, $I_{\mathrm{p}}$ is the polar moment of area at the thread root, $d_{2}$ is the basic pitch diameter of the threads, $\alpha$ is the half of thread profile angle, $\mu_{\mathrm{t}}$ is the friction coefficient between the contact threads, and $P$ is the pitch of the threads. The values of the above-mentioned parameters are listed in Tab. 1.

From the dimensions of the bolt, friction coefficient between the contact threads, and Eqs. (4) and (5) into Eq. (3), the equivalent stress at the thread root can be determined when a preload of $18 \mathrm{kN}$ is applied to the uncoated bolt, and then the preload for the coated $\mathrm{MoS}_{2}$ bolt, which results in the same equivalent stress as that of the uncoated bolt at the thread root, can be determined as

$$
P_{0}=21.5 \mathrm{kN}
$$

Tab. 1 Bolt dimensional details and friction coefficients between the contact threads

\begin{tabular}{ll}
\hline Thread diameter, $D$ & $12.000 \mathrm{~mm}$ \\
Thread pitch, $P$ & $1.750 \mathrm{~mm}$ \\
Minor diameter of thread, $d_{1}$ & $10.106 \mathrm{~mm}$ \\
Basic pitch diameter of thread, $d_{2}$ & $10.863 \mathrm{~mm}$ \\
Half of thread profile angle, $\alpha$ & $30^{\circ}$ \\
For the uncoated bolt, friction coefficient ${ }^{[66]}, \mu_{\mathrm{t}}$ & 0.169 \\
For the $\mathrm{MoS}_{2}$ coated bolt, friction coefficient ${ }^{[66]}, \mu_{\mathrm{t}}$ & 0.083 \\
\hline
\end{tabular}

Fig. 14 shows the OM morphologies of first three $\mathrm{MoS}_{2}$ coated thread surfaces for the preload of $21.5 \mathrm{kN}$. Likewise, with the increasing thread sequence, the damage of thread surface gets slight, and the damage of the first thread is most serious. Compared with Fig. 9(b), the damage is reduced when the preload is $21.5 \mathrm{kN}$.

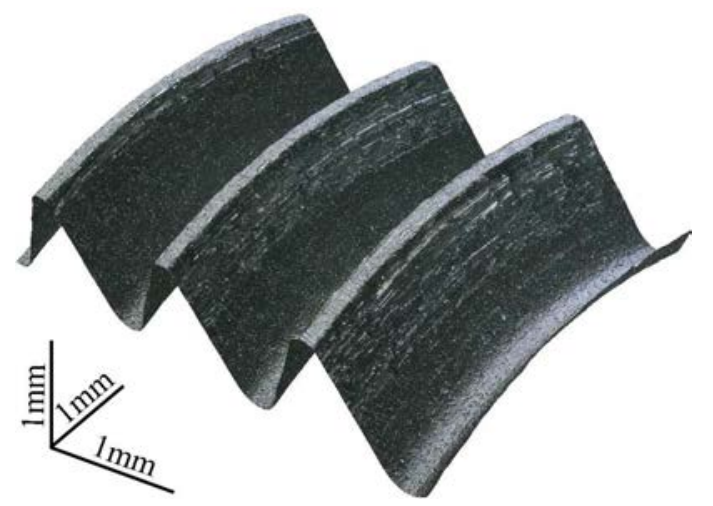

Fig. 14. OM morphologies of first three thread surfaces of the $\mathrm{MoS}_{2}$ bolted joint:

$$
\left(P_{0}=21.5 \mathrm{kN}, A_{\mathrm{F}}=10 \mathrm{kN}\right)
$$

Fig. 15 shows the SEM images and EDS analyses of the first thread surface of the $\mathrm{MoS}_{2}$ coated bolt at a preload of $21.5 \mathrm{kN}$. Similarly, there are many $\mathrm{MoS}_{2}$ particles on the thread surface, and 


\section{ACCEPTED MANUSCRIPT}

delamination are the secondary wear phenomena. The EDS analyses show that the $\mathrm{MoS}_{2}$ coating is completely removed in a local area. Therefore, abrasive wear and delamination are the main wear mechanisms.

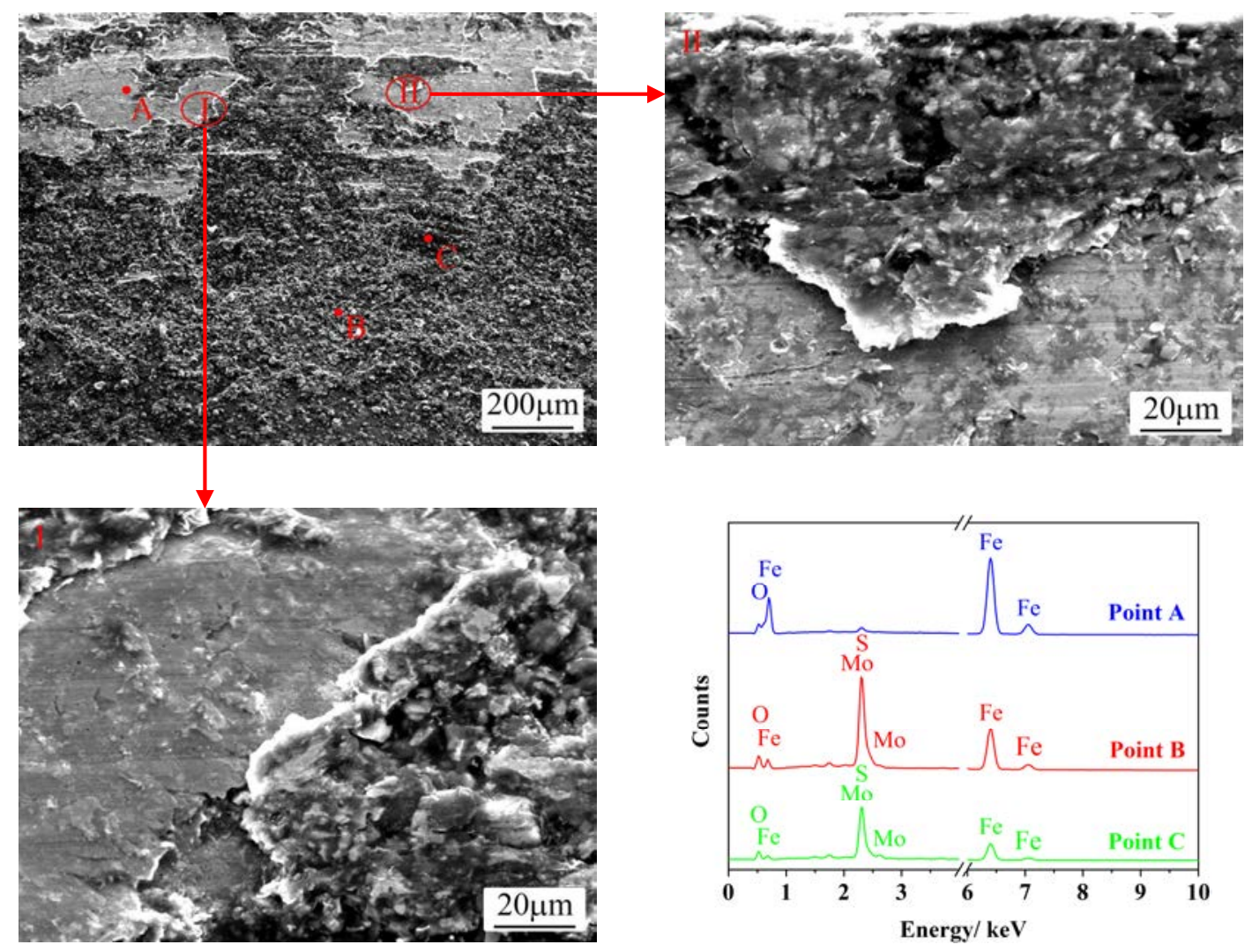

Fig. 15. SEM images and EDS analyses of the first thread surface of the $\mathrm{MoS}_{2}$ bolted joint:

$$
\left(P_{0}=21.5 \mathrm{kN}, A_{\mathrm{F}}=10 \mathrm{kN}\right)
$$

As can be seen from Fig. 16, the anti-loosening performance of the $\mathrm{MoS}_{2}$ coated bolt is best when a preload of $21.5 \mathrm{kN}$ is applied to the bolt. The higher preload is applied to the bolt, the more asperities deform plastically, diminish in size, or are even removed during the tightening process, and thus the change in clamping force is smaller in Stage I. In addition, fretting wear gets slight due to the self-lubrication of the $\mathrm{MoS}_{2}$ coating. Therefore, the clamping force decreases slowly.
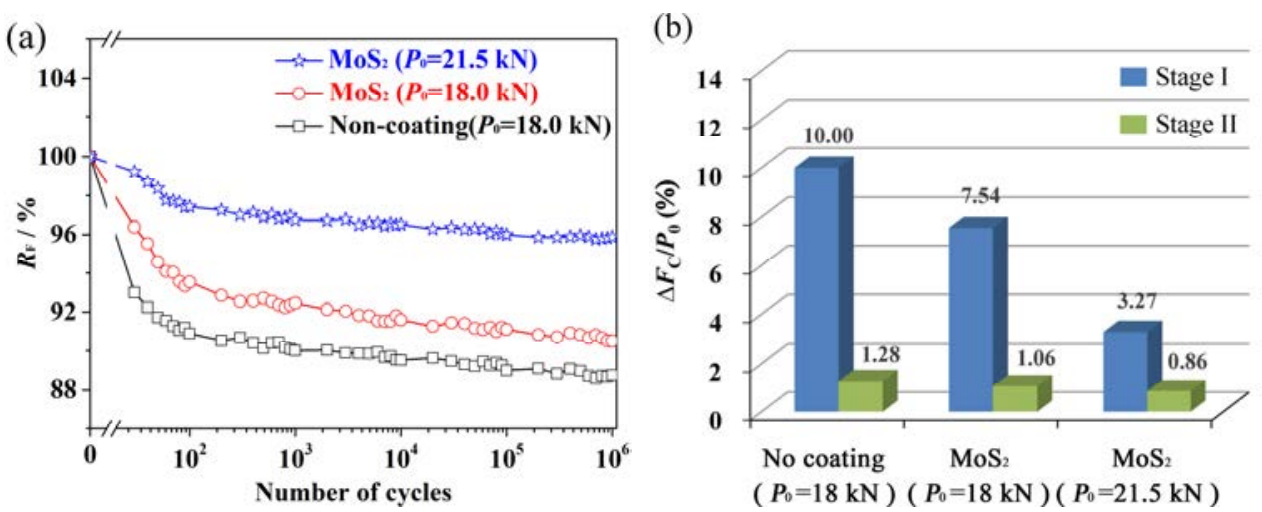

Fig. 16. Self-loosening curves and reductions of clamping forces for varying test parameters $\left(A_{\mathrm{F}}=10 \mathrm{kN}\right)$ : (a) Self-loosening curves; (b) Reductions of clamping forces 


\section{Description of finite element model}

Fig. 17 shows the finite element model used in this study. The model contains two fixtures, a load cell, a bolt and a nut. The material of the first three parts is considered elastic, and its Young's modulus is $210 \mathrm{GPa}$. The material of bolt and nut is considered elasto-plastic, and the stress-strain curve is obtained by uniaxial tensile tests. In addition, Poisson's ratio of all materials is taken as 0.3. In order to save calculation time, seven threads are built up for the bolt and six threads are created for the nut in this model.

Tetrahedral elements (C3D4R) are used in the transition region between the cylindrical part and the rectangular box of each of the two fixtures, while eight-node linear reduced-integration hexahedral elements (C3D8R) are used in the other regions to improve the accuracy of the calculation. There are 471,445 nodes and 424,473 elements in the FE model.

Five contact pairs are defined in this finite element model. They are the contact between the head of the bolt and the top fixture (Contact I), the contact between the top fixture and the load cell (Contact II), the contact between the load cell and the lower fixture (Contact III), the contact between the lower fixture and the nut (IV) and the contact between the threads (V). Considering that separation may occur between the top fixture and the load cell under axial excitation, the finite sliding formulation is used for Contact II and Contact III. In order to improve the efficiency of computation, the small sliding formulation is selected for the other contact pairs. For Contact V, an exponential pressure-overclosure relationship is selected for the normal behaviour and the penalty method with friction is used for the tangential behaviour. For the other contact pairs, the penalty methods with hard contact and friction are respectively used for the normal and tangential behaviour. The friction coefficient between the contact pairs is taken as 0.15 for Contact II, Contact III and Contact IV. Based on the experimental results ${ }^{[66]}$, the friction coefficients between the bearing surfaces (Contact I) and between the threads (Contact V) are listed in Tab. 2.

(a)

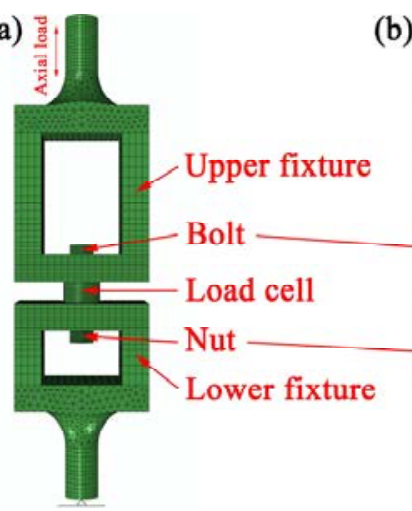

(b)

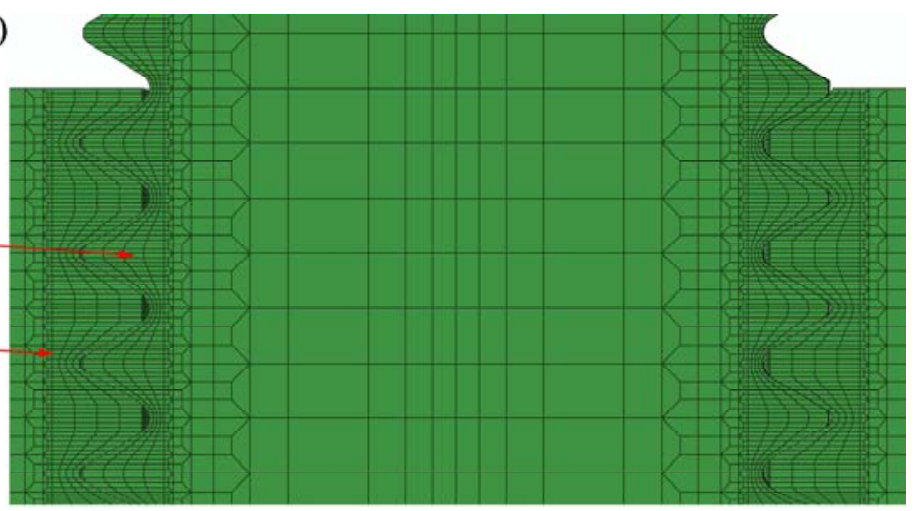

Fig. 17. Finite element model: (a) Complete model; (b) Enlarged view of the threads

The process of applying boundary conditions and loading is as follows:

(1) The end of the lower fixture is fixed, and the top fixture and the nut are not allowed to twist around the vertical axis and to move in the horizontal direction in the initial step.

(2) In order to avoid singularity in the numerical computation, an angular displacement of 0.005 rad around the bolt axis is applied to the bolt head in the first step.

(3) The angular displacement listed in Tab. 2 is applied to the bolt head, and the constraints of the 
top fixture and the nut are released in the second step.

(4) The axial excitation is applied to the end of the top fixture in the next six steps (see Fig. 18 and Tab. 2).

Tab. 2. Finite element simulations ${ }^{[66]}$

\begin{tabular}{cccccc}
\hline $\begin{array}{c}\text { Loading } \\
\text { case }\end{array}$ & $\begin{array}{c}\text { Friction } \\
\text { coefficient } \boldsymbol{\mu}_{\mathrm{h}}\end{array}$ & $\begin{array}{c}\text { Friction } \\
\text { coefficient } \boldsymbol{\mu}_{\mathrm{t}}\end{array}$ & $\begin{array}{c}\text { Tightening } \\
\text { angle (rad) }\end{array}$ & Preload (kN) & $\begin{array}{c}\text { Excitation } \\
\text { amplitude }(\mathrm{kN})\end{array}$ \\
\hline 1 & 0.269 & 0.169 & 0.250 & 15 & 10 \\
2 & 0.269 & 0.169 & 0.295 & 18 & 10 \\
3 & 0.269 & 0.169 & 0.340 & 21 & 10 \\
4 & 0.269 & 0.169 & 0.295 & 18 & 7.5 \\
5 & 0.269 & 0.169 & 0.295 & 18 & 12.5 \\
6 & 0.083 & 0.045 & 0.288 & 18 & 10 \\
7 & 0.081 & 0.078 & 0.291 & 18 & 10 \\
8 & 0.296 & 0.418 & 0.328 & 18 & 10 \\
9 & 0.081 & 0.078 & 0.338 & 21.5 & 10 \\
\hline
\end{tabular}

( $\mu_{\mathrm{h}}$ denotes the friction coefficient between the bolt head and the top fixture, and $\mu_{\mathrm{t}}$ denotes the friction coefficient between the contact threads)

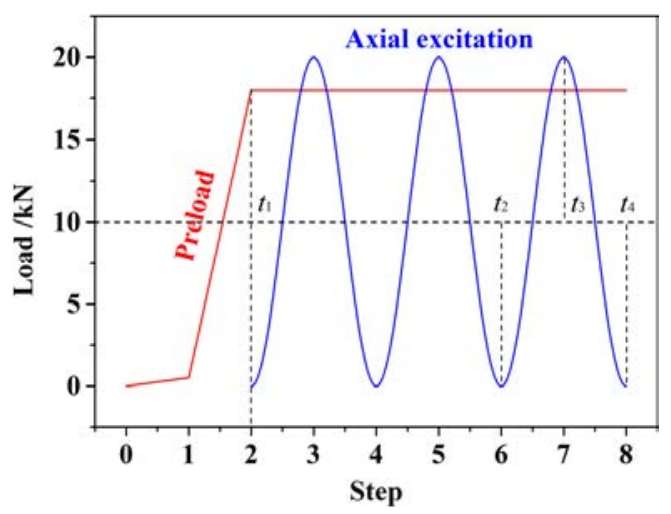

Fig. 18. Loading process

\section{Numerical results}

\subsection{Verification of finite element model}

Yamamoto ${ }^{[67]}$ theoretically investigated the axial-load distribution on each thread, and also gave its mathematical expression. Fig. 19 shows the axial-load distributions from the finite element method and theoretical method. As can be seen from the figure, very good agreement is achieved between the numerical results and the theoretical results. It is found from the numerical results that the first thread carries $30 \%$ of the total axial-load. For further threads, the load carried by each thread decreases gradually.

Fig. 20 shows the stress concentration factor (SCF) at the thread roots. The maximum value of SCF occurs at the first thread root of the bolt. This is one of the reasons why fatigue fracture occurs there. In addition, the distribution of SCF along the thread roots of the nut is smoother than that of bolt. This is one of the reasons why bolts, not nuts, are usually prone to fatigue fracture. 


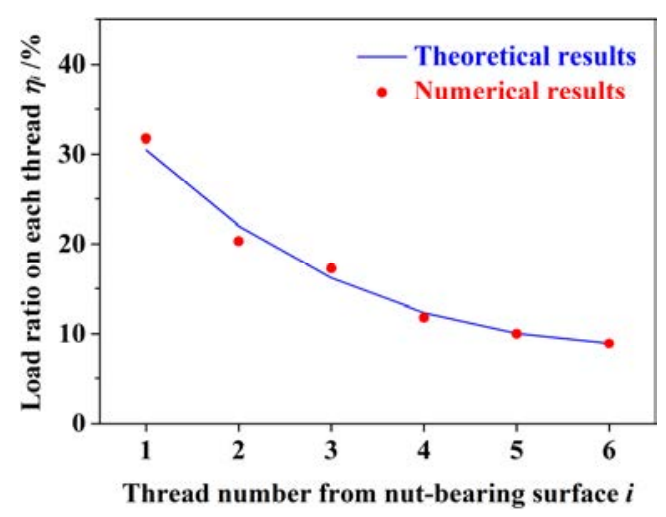

Fig. 19. Comparison of axial-load distributions from the theoretical and numerical methods

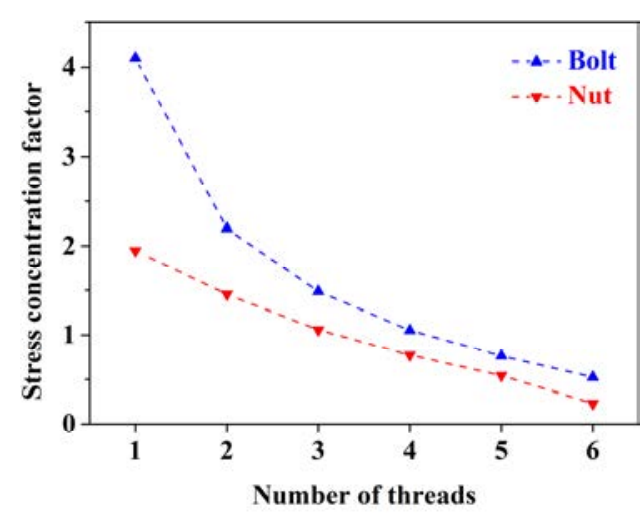

Fig. 20. The SCF distributions along the thread roots for bolt and nut

The theoretical relationships between the tightening/loosening torques and preload are wellknown and given as ${ }^{[65,68]}$ :

$$
\begin{aligned}
T_{\mathrm{t}} & \approx \frac{P_{0}}{2}\left(\frac{d_{2}}{\cos \alpha} \mu_{\mathrm{t}}+\frac{P}{\pi}\right)+\frac{P_{0}}{2} d_{w} \mu_{\mathrm{h}} \\
& =T_{\text {thread }}+T_{\text {pitch }}+T_{\text {head }} \\
T_{1} & \approx \frac{P_{0}}{2}\left(\frac{d_{2}}{\cos \alpha} \mu_{\mathrm{t}}-\frac{P}{\pi}\right)+\frac{P_{0}}{2} d_{w} \mu_{\mathrm{h}} \\
& =T_{\text {thread }}-T_{\text {pitch }}+T_{\text {head }}
\end{aligned}
$$

where $T_{\mathrm{t}}$ and $T_{1}$ are defined as the tightening torque and the loosening torque, $P_{0}$ is the preload, $d_{2}$ is the basic pitch diameter of the threads, $\alpha$ is the half of thread profile angle, $d_{w}$ is the equivalent diameter of bearing surface, $T_{\text {thread }}$ is the bolt thread torque due to friction between the contact threads, $T_{\text {pitch }}$ is the bolt thread torque due to thread pitch, and $T_{\text {head }}$ is the head torque due to friction between the clamped plate and the head of the bolt.
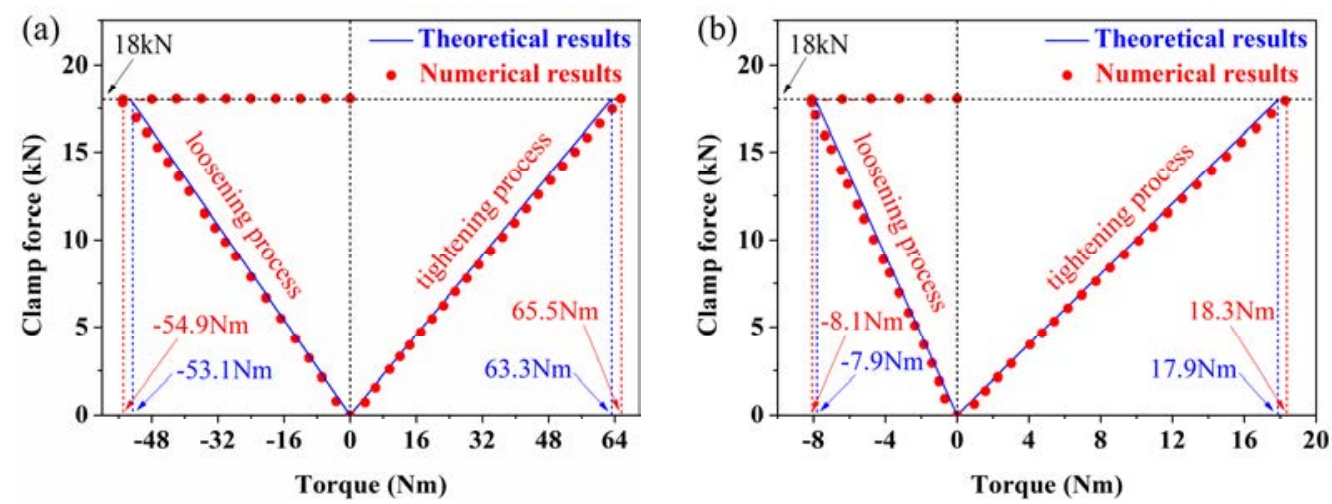

Fig. 21. Relationships between clamping force and tightening/loosening torque:

(a) $\mu_{\mathrm{h}}=0.269, \mu_{\mathrm{t}}=0.169 ;$ (b) $\mu_{\mathrm{h}}=\mu_{\mathrm{t}}=0.05$

Fig. 21 shows the relationship between the tightening/loosening torques and the preload. It is found from the numerical results that the loosening torque is smaller than the tightening torque. In addition, $T_{\text {pitch }}$ is small, which indicates that the total torque is used to overcome the friction torques both on the contact threads and on the bearing surfaces. As can be seen from Fig. 21(b), the loosening torque is smaller than $50 \%$ of the tightening torque. The tightening/loosening torque decreases with the decrease of the friction coefficients between the contact surfaces. Once the friction coefficients are small enough, the loosening torque may be equal to zero, and the bolted 
joint will lose the self-locking performance. From the numerical results and theoretical results (Figs. 19 and 21), the finite element model is valid.

\subsection{The tightening process}

Fig. 22 shows the plastic deformation by two possible methods to apply a bolt preload in ABAQUS. For the method of applying a preload of $18 \mathrm{kN}$ over the bolt cross-section (the first method), the plastic deformation at the thread roots is smaller than that for the method of applying the same preload by twisting the head of the bolt (the second method). As shown in Fig. 23, the contact stress, the equivalent stress, and the shear stress on the threads for the first method are all larger than those for the second method. In practice, a bolt preload is usually applied by twisting the head of the bolt using a torque wrench. Additionally, the contact stress and the shear stress have direct influences on the fretting wear and the contact state on the threads. Consequently, the second method is used to apply a bolt preload in the subsequent numerical analysis.

(a)

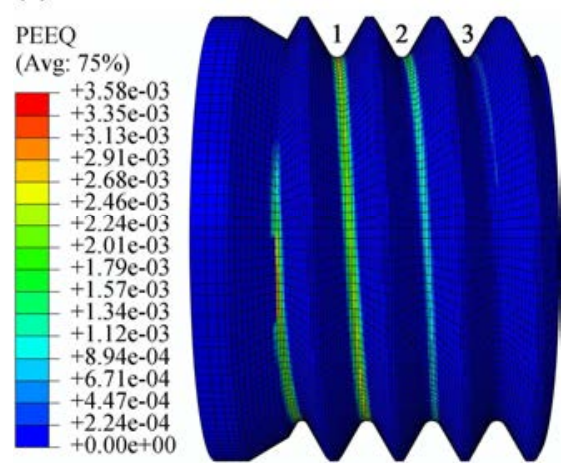

(b)

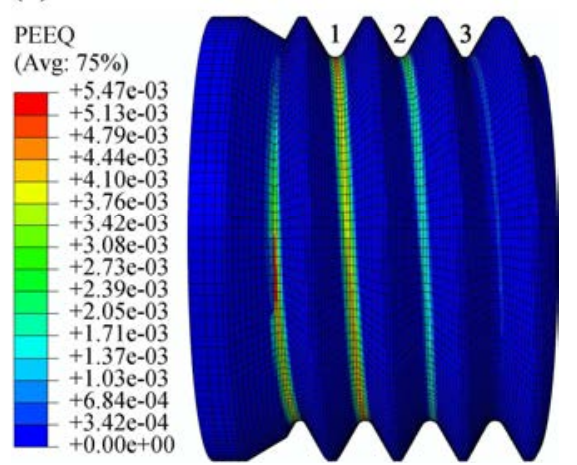

(a) Applying a bolt preload over the bolt cross-section; (b) Applying a bolt preload by twisting the head of the bolt

Fig. 22. Plastic deformation for two methods to apply a bolt preload $\left(P_{0}=18 \mathrm{kN}\right)$ :

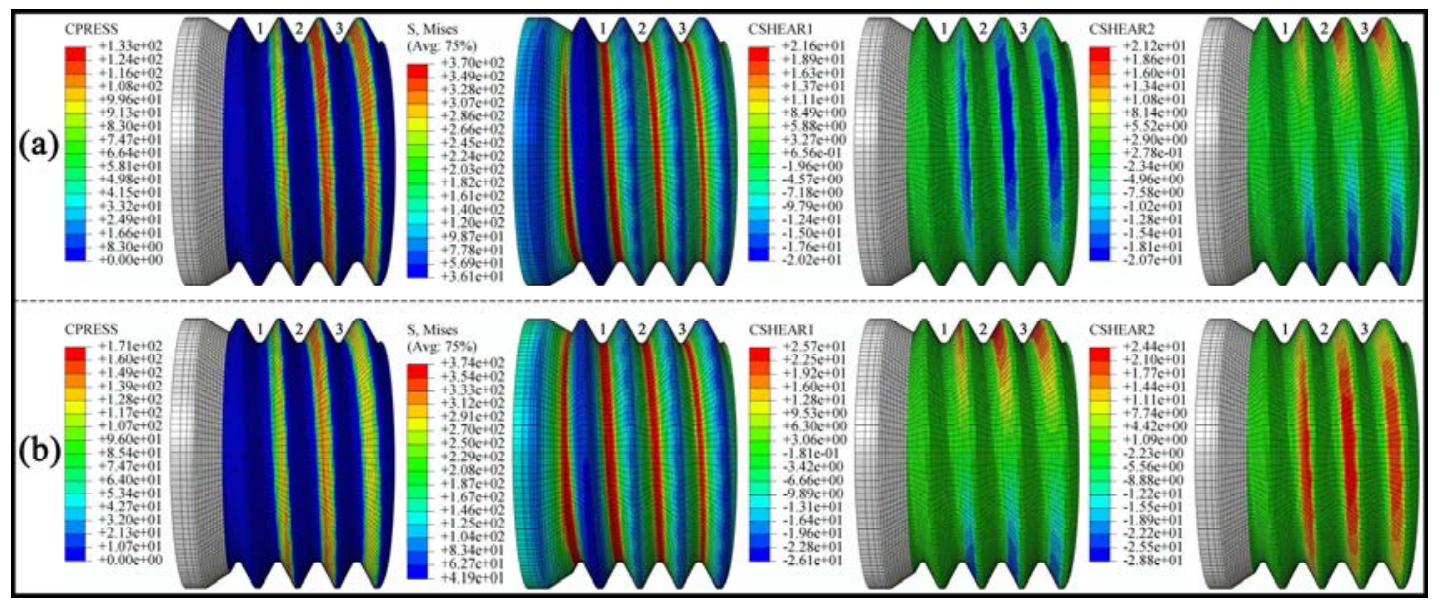

(a) Applying a bolt preload over the bolt cross-section; (b) Applying a bolt preload by twisting the head of the bolt

Fig. 23. Stress distributions on the threads under the preload $\left(P_{0}=18 \mathrm{kN}\right)$ :

It is important to note that applying a bolt preload by twisting the head of the bolt can be conducted under torque control or angle control. Fig. 24 shows the preload-tightening torque 
curves for different friction coefficients between the head of the bolt and the top fixture and between the threads. Loading case 2, 6, 7 and 8 separately simulate the loading process for the uncoated bolt, the PTFE coated bolt, the $\mathrm{MoS}_{2}$ coated bolt and the TiN coated bolt. As can be seen from the figure, due to application of a bolt preload of $18 \mathrm{kN}$, the tightening torque for the PTFE coated bolt is smallest, and that for the TiN bolt coated bolt is largest and it is nearly 1.5 times as large as that for the uncoated bolt. In addition, the preload for the coated TiN bolt is equal to zero in the initial stage of tightening process. This is because relative slip between the contact surfaces does not occur and the length of the bolt remains constant due to the high friction coefficients. When the tightening torque reaches a certain value, a relative slip occurs and the length of the bolt increases, and then the preload increases. Consequently, the friction coefficients between the bolt head and the top fixture and between the threads have a big effect on the preload-tightening torque curves.

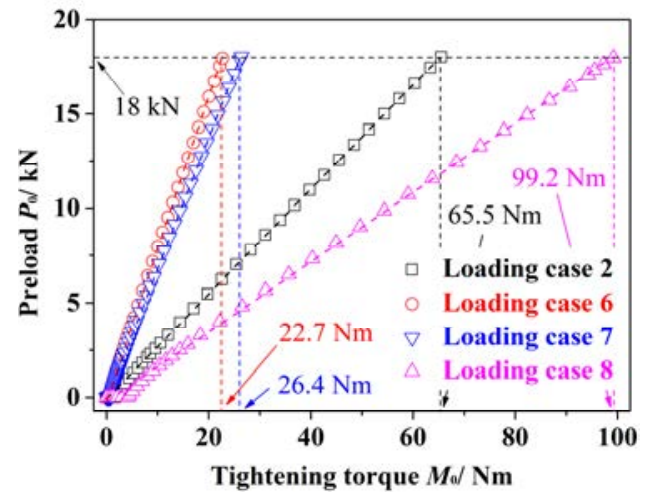

Fig. 24. Preload-tightening torque curves

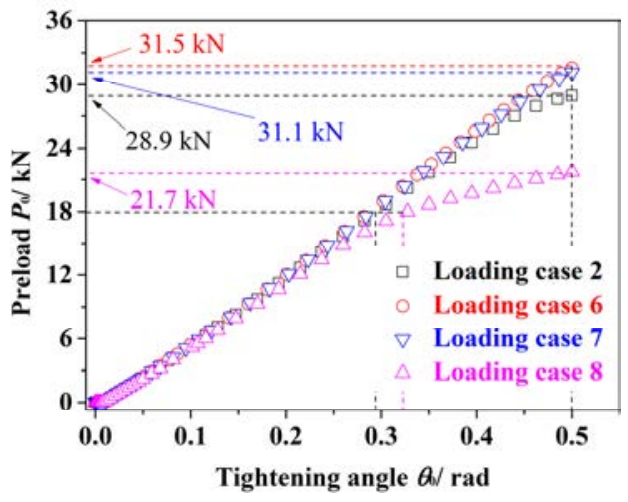

Fig. 25. Preload-tightening angle curves

Fig. 25 shows the preload-tightening angle curves for different friction coefficients between the head of the bolt and the top fixture and between the threads. When the tightening angle is less than $0.3 \mathrm{rad}$, the preload-tightening angle curves show little difference, and the preload is linear with the tightening angle. Therefore, the friction coefficients between the contact surfaces have a small effect on the preload-tightening angle curves when the tightening angle is small. For the TiN coated bolt, the preload does not appear have a linear relationship with the tightening angle when the tightening angle is greater than $0.3 \mathrm{rad}$, and the preload is smaller than that for the other bolts. This is because severe plastic deformation occurs at the thread roots due to the high friction torque. In order to verify this conclusion, the plastic deformations at the thread roots in varying loading cases is analysed at a tightening angle of $0.5 \mathrm{rad}$.

(a)

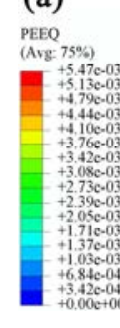

(b)

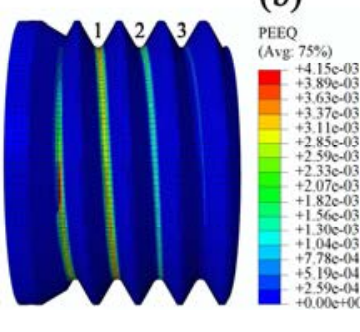

(c)

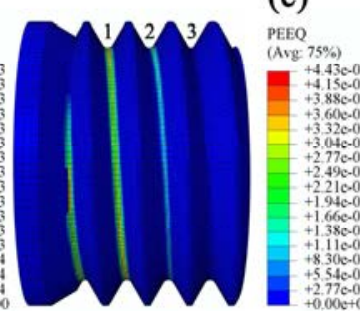

(d)

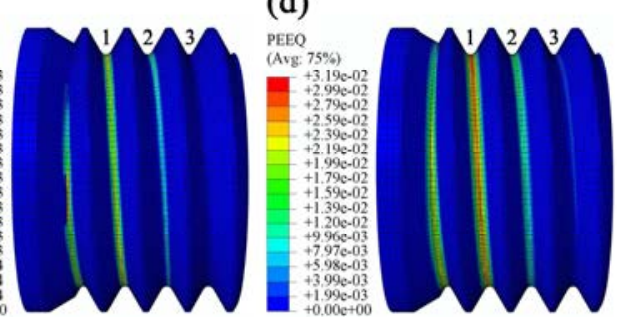

Fig. 26. Plastic deformation for varying loading cases $\left(\theta_{0}=0.5 \mathrm{rad}\right)$ :

(a) Loading case 2; (b) Loading case 6; (c) Loading case 7; (d) Loading case 8 
Fig. 26 shows the plastic deformation in varying loading cases. It is found from the figure that the maximum plastic deformation for the PTFE/MoS 2 coated bolt is small and that for the TiN coated bolt is nearly six times that for the uncoated bolt.

\subsection{Dynamic behaviour of bolted joints}

\subsubsection{Effect of preload}

Fig. 27 shows the changes in the axial displacement of the end of the top fixture under the axial excitation at different preloads in the third analysis step. It is found from the figure that the response curves are almost coincident under different preloads when the value of axial excitation is less than $15 \mathrm{kN}$, and the axial displacement of the end of the top fixture for the preload of $15 \mathrm{kN}$ is larger than that for the other two preloads when the value of axial excitation is larger than $15 \mathrm{kN}$. Fig. 28 shows the variations of axial load and clamping force under applied axial excitation at different preloads. Under the preload of $15 \mathrm{kN}$, it is found that axial load on the bolt cross-section increases slowly and clamping force decreases quickly when the applied axial excitation is less than $15 \mathrm{kN}$, and axial load increases quickly and clamping force is equal to zero, which means that all the axial excitation goes to the bolt due to the separation of the top fixture from the load cell. Under the preload of $18 \mathrm{kN}$, the top fixture is separated from the load cell when the axial excitation reaches $18.5 \mathrm{kN}$. It is found that the separation of the top fixture and the load cell does not occur under the preload of $21 \mathrm{kN}$ until the axial excitation reaches $20 \mathrm{kN}$.

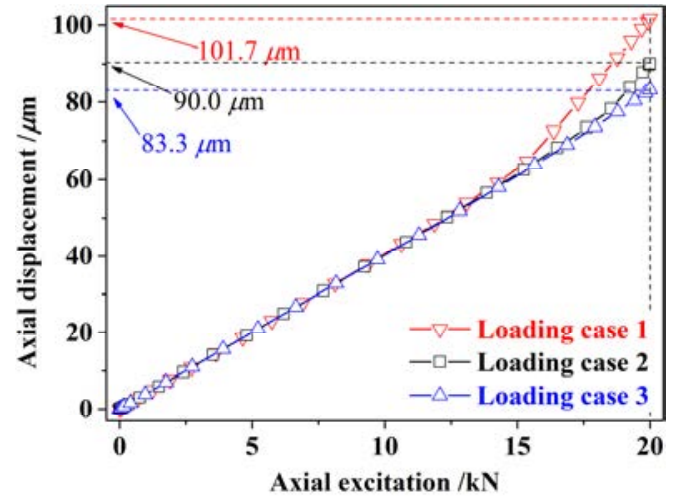

Fig. 27. Response curves in the third analysis step at different preloads

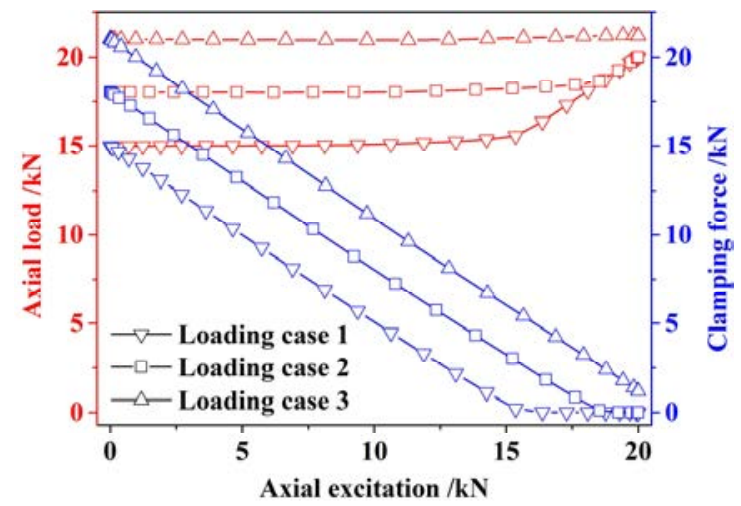

Fig. 28. Variations of axial load and clamping force with the axial excitation

In Fig. 29, two paths are defined on the bolt thread surface to further investigate the frictional stress at $t_{3}$, slip amplitude and dissipated frictional energy per unit area (hereinafter referred to as dissipated frictional energy) during a loading cycle in detail. They are Path 1 and Path 2 in red colour, which are in the radial and circumferential direction. Additionally, a point on Path 1, denoted by $\mathrm{A}$, is selected to study the relative slippage in the first loading cycle.

Fig. 30 shows the variations of clamping force, maximum cumulative plastic deformation caused by axial excitation at the thread roots and the relative slippage at point A (Fig. 29) for varying preloads. Function $\Delta \varepsilon_{\mathrm{p}}(3)$ is defined as maximum cumulative plastic deformation in the first three loading cycles, and $\Delta S_{\mathrm{A}}(1)$ is defined as relative slippage at point $\mathrm{A}$ in the first loading cycle. It is found from the numerical results that a micro slippage at point $\mathrm{A}$ occurs in the loosening direction during the first loading process and it is not completely recovered during the 
unloading process, which causes the clamping force to decrease, while the micro slippage in the loosening direction can be almost completely recovered during the unloading process in the next analysis steps. Consequently, in the subsequent analysis, relative slippage at point $\mathrm{A}$ is only analysed in the first loading cycle. As can be seen from Fig. 30, with the increasing preload, the maximum cumulative plastic deformation at the thread roots and the relative slippage at point $\mathrm{A}$ decrease, and the ratio of the residual axial load of the bolt to preload increases.

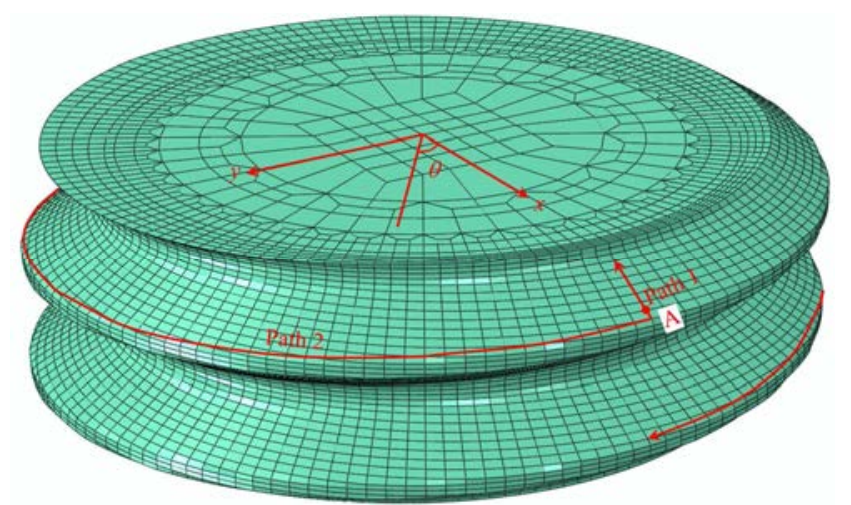

Fig. 29. Definition of the two paths

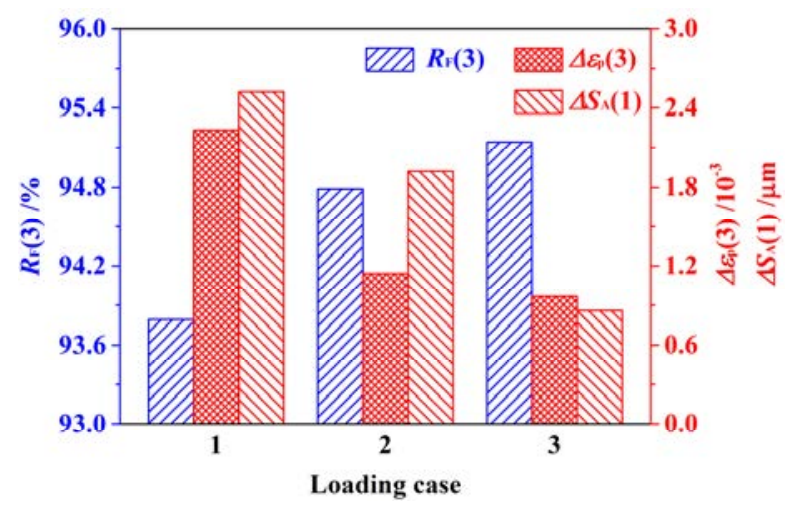

Fig. 30. Variations of clamping force, maximum cumulative plastic deformation at the thread roots and relative slippage at point $\mathrm{A}$ for varying preloads

Fig. 31 shows the frictional stress at $t_{3}$, displacement amplitude and dissipated frictional energy (from $t_{2}$ to $t_{4}$ ) along Path 1 at varying preloads. As can be seen from Fig. 31(a), the frictional stress is largest at point $\mathrm{A}$ and the displacement amplitude at the thread root and crest is larger than that in the other area along Path 1. As discussed before, the top fixture is separated from the load cell and all the axial excitation adds to the bolt at $t_{3}$ when the preload is $15 \mathrm{kN}$ and $18 \mathrm{kN}$. Thus, the frictional stress remains constant at the beginning, and it increases when the preload is large enough to prevent it from separation of the top fixture from the load cell. In addition, under high preload, slip between the contact threads is not easy to occur under the same axial excitation, so the displacement amplitude decreases obviously with the increasing preload. It is found from Fig. 31(b) that the dissipated frictional energy increases with the decreasing preload and it is largest at point A.

Fig. 32 shows the frictional stress at $t_{3}$, the displacement amplitude and the dissipated frictional energy (from $t_{2}$ to $t_{4}$ ) along Path 2 at varying preloads. It is found from the numerical results that the frictional stress decreases along Path 2. In addition, the displacement amplitude 
decreases overall, but not monotonically along Path 2 . This is because the bolt is subjected to not only an axial load but also bending moments on the left and right sides of the top fixture under axial excitation (Fig. 17(a)), which causes the displacement amplitude on the left and right sides of the top fixture to be larger than that in the other area of the same thread. As shown in Fig. 32(b), the dissipated frictional energy decreases along Path 2, and it decreases with the increasing preload.

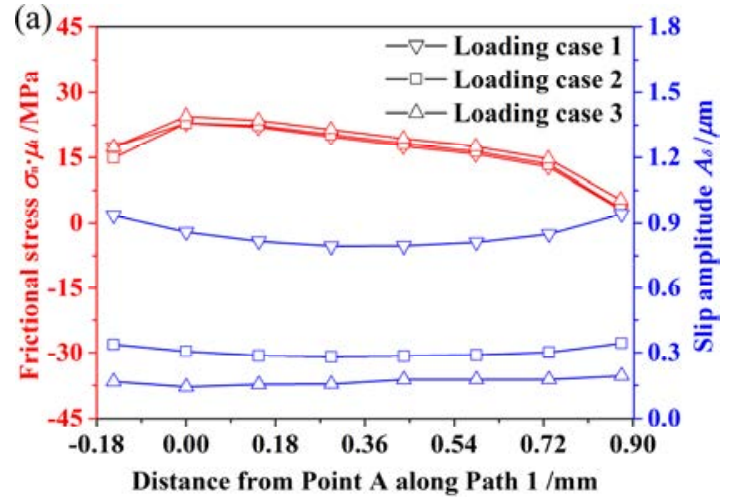

(a) Frictional stress at $t_{3}$ and displacement amplitude

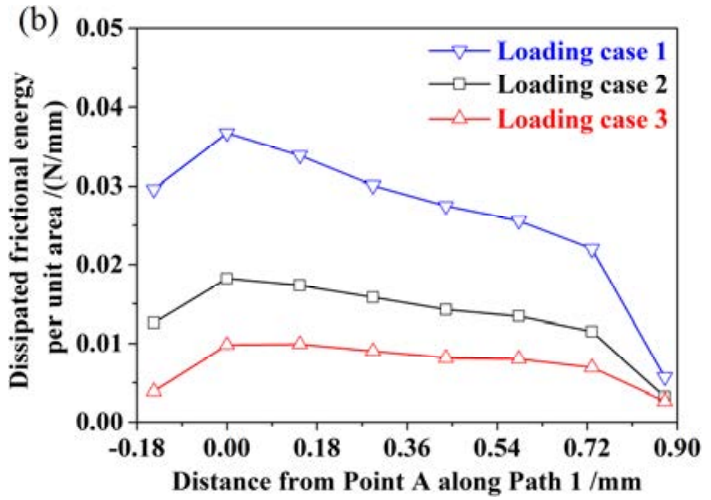

(b) Dissipated frictional energy

Fig. 31. Frictional stress at $t_{3}$, displacement amplitude and dissipated frictional energy along Path 1 at varying preloads

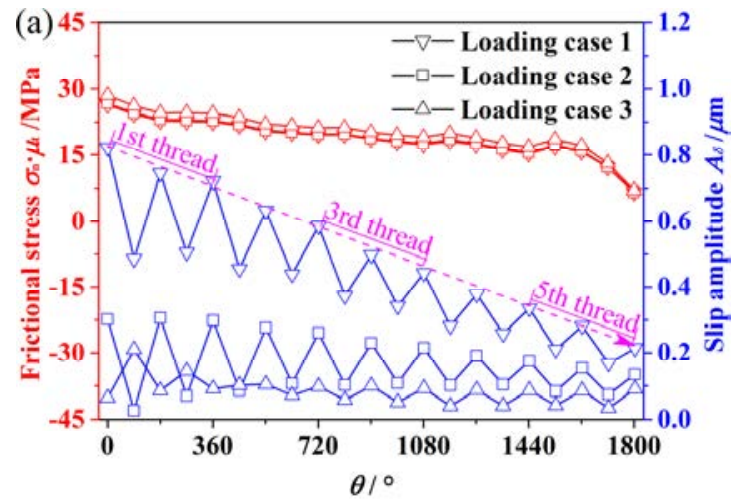

(a) Frictional stress at $t_{3}$ and displacement amplitude

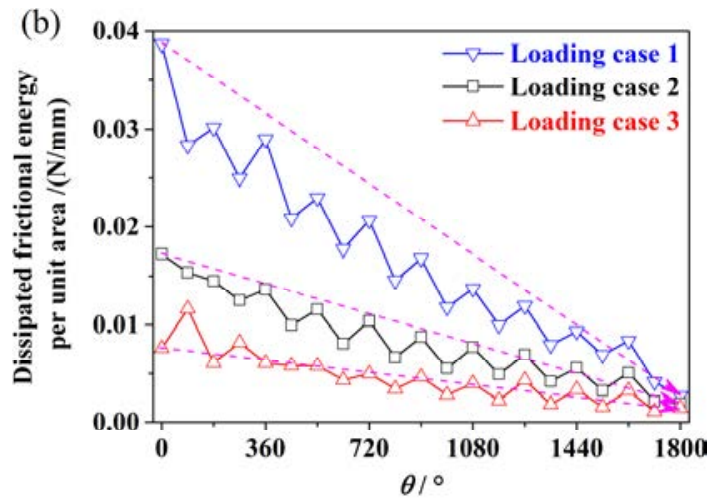

(b) Dissipated frictional energy

Fig. 32. Frictional stress at $t_{3}$, displacement amplitude and dissipated frictional energy along Path 2 at varying preloads:

\subsubsection{Effect of excitation amplitude}

As shown in Fig. 33, with the increasing excitation amplitude, the maximum cumulative plastic deformation at the thread roots and the relative slippage at point A increase, and then the ratio of the residual clamping force to preload decreases.

Fig. 34 and Fig. 35 illustrate the frictional stress at $t_{3}$, displacement amplitude and dissipated frictional energy (from $t_{2}$ to $t_{4}$ ) along Path 1 and Path 2 at three levels of excitation amplitude. Similarity, the frictional stress and dissipated frictional energy are largest at point A along Path 1, and they decrease overall along Path 2. The displacement amplitude at the thread root and crest is larger than that in the other area along Path 1, and it also decreases overall along Path 2. With the increase of excitation amplitude, the frictional stress, the displacement amplitude and the dissipated frictional energy increase. 


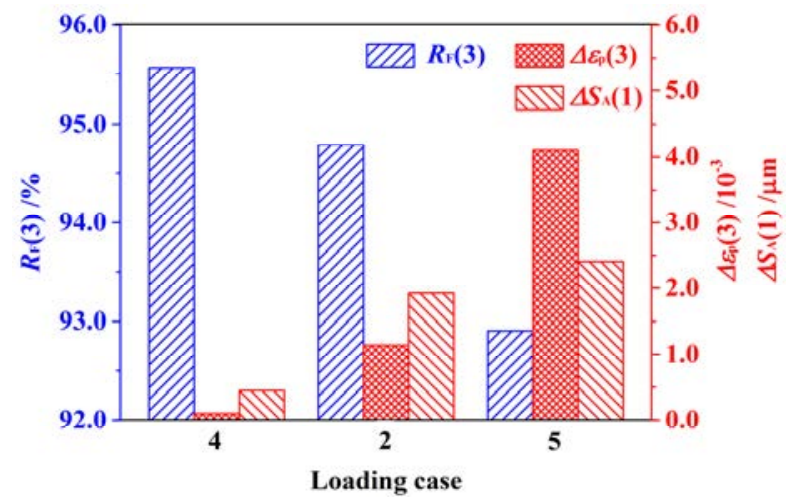

Fig. 33. Variations of clamping force, maximum cumulative plastic deformation at the thread roots and relative slippage at point $\mathrm{A}$ for varying excitation amplitudes

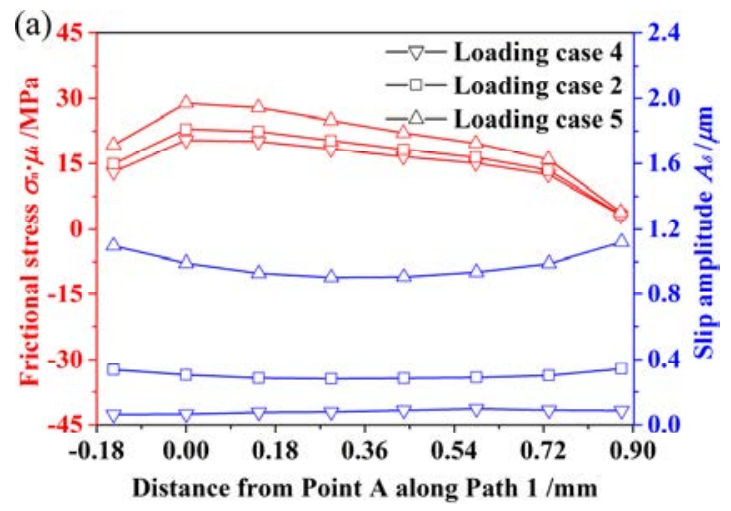

(a) Frictional stress at $t_{3}$ and displacement amplitude

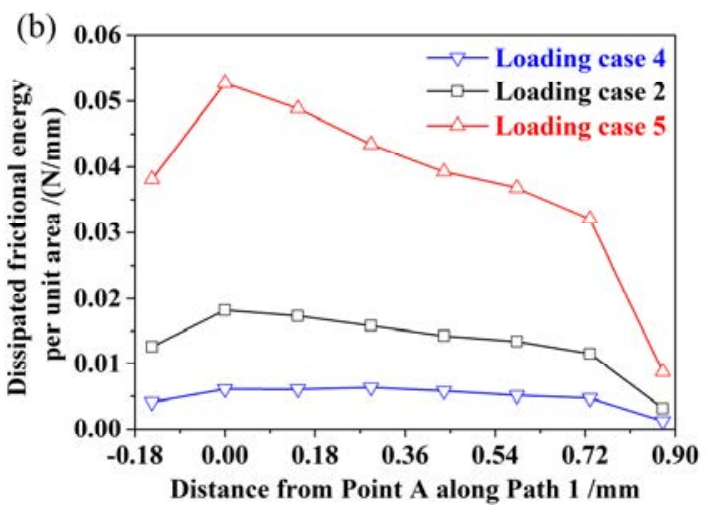

(b) Dissipated frictional energy

Fig. 34. Frictional stress at $t_{3}$, displacement amplitude and dissipated frictional energy along Path 1 at three levels of excitation amplitude

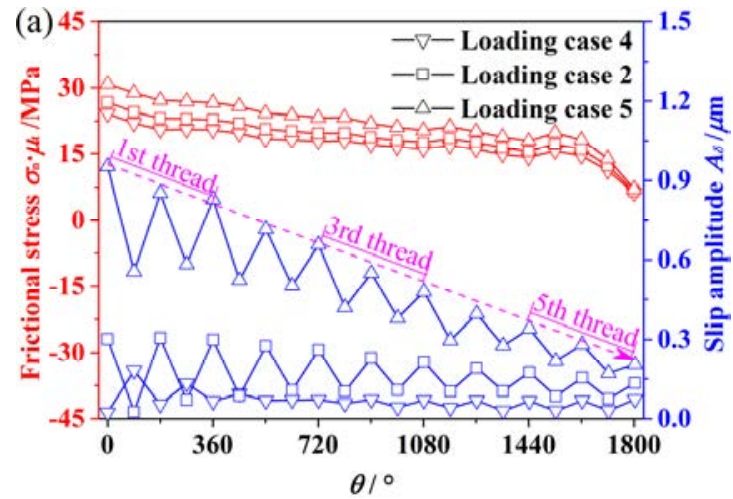

(a) Frictional stress at $t_{3}$ and displacement amplitude

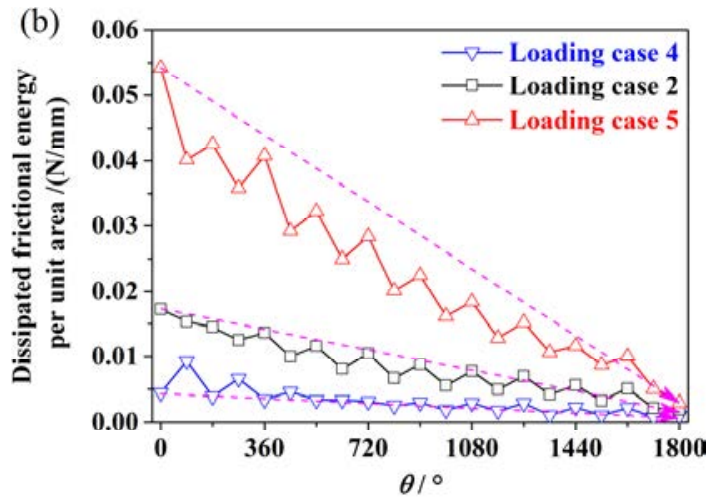

(b) Dissipated frictional energy

Fig. 35. Frictional stress at $t_{3}$, displacement amplitude and dissipated frictional energy along Path 2 at three levels of excitation amplitude

\subsubsection{Effect of friction coefficients between the contact surfaces}

The behaviour of the PTFE/MoS$/$ TiN coated bolt is studied by changing the friction 
coefficients between the contact surfaces. Fig. 36 shows the variations of clamping force, maximum cumulative plastic deformation at the thread roots and relative slippage at point $\mathrm{A}$ for varying friction coefficients between the contact surfaces. With the friction coefficients between the contact surfaces increase, the maximum cumulative plastic deformation at the thread roots and the relative slippage at point A decrease, and then the ratio of the residual axial load of the bolt to preload increases. It is important to note that the asperities on the thread surface are not considered in the finite element model. In practice, the friction coefficient is closely related to the asperities, which also have a great effect on the reduction of clamping force.

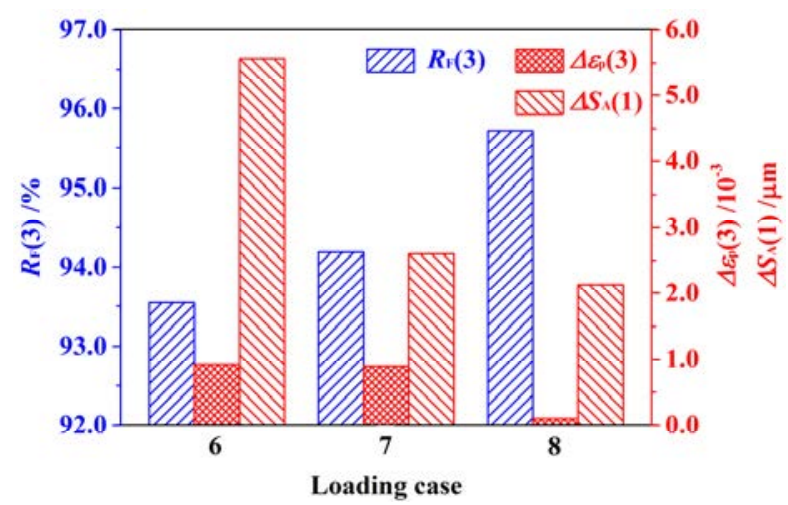

Fig. 36. Variations of clamping force, maximum cumulative plastic deformation at the thread roots and relative slippage at point $\mathrm{A}$ for varying friction coefficients between the contact surfaces

Fig. 37 and Fig. 38 show the frictional stress at $t_{3}$, displacement amplitude and dissipated frictional energy (from $t_{2}$ to $t_{4}$ ) along Path 1 and Path 2 for varying friction coefficients between the contact surfaces. With the increase of the friction coefficients, the friction stress increases, and then slip is not easy to occur between the contact threads. In addition, the dissipated frictional energy increases with the increase of friction coefficients. It is important to note that the wear resistance of coating and the bonding strength between coating and bolt matrix are excluded in the finite element model, so it cannot be claimed that the thread damage of the TiN coated bolt is more serious than that of the PTFE/MoS 2 coated bolt.

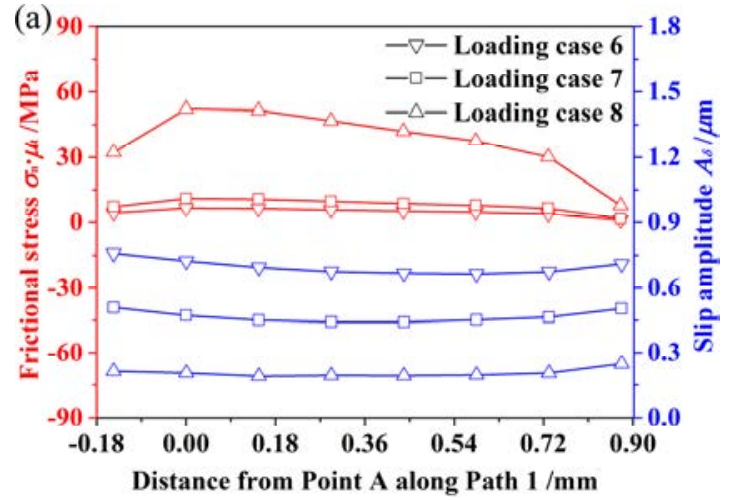

(a) Frictional stress at $t_{3}$ and displacement amplitude

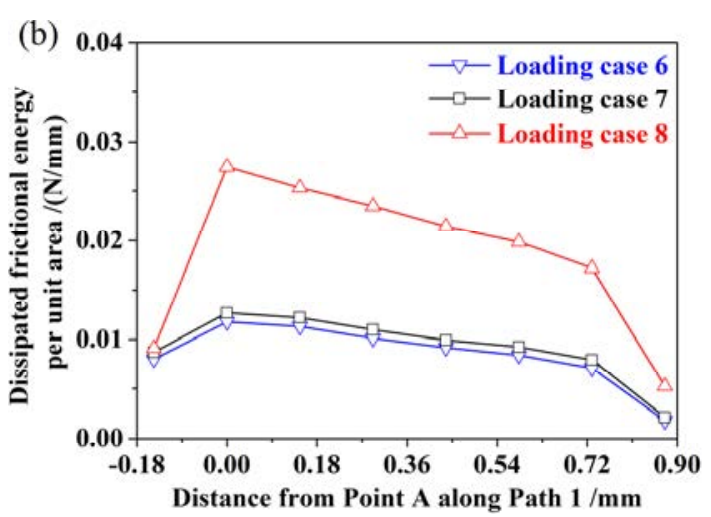

(b) Dissipated frictional energy

Fig. 37. Frictional stress at $t_{3}$, displacement amplitude and dissipated frictional along Path 1 for varying friction coefficients between the contact surfaces 
As can be seen from Fig. 25, the preload for the TiN coated bolt is not linear with the tightening angle when it reaches $15 \mathrm{kN}$. This suggests that severe plastic deformation has occurred during the tightening process, and there is a risk of fracture failure for the TiN coated bolt. It is found from the numerical results that the dissipated frictional energy for the $\mathrm{MoS}_{2}$ coated bolt is slightly larger than that for the PTFE coated bolt. However, the bonding strength of $\mathrm{MoS}_{2}$ coating is much higher than that of PTFE coating ${ }^{[55,58]}$. Consequently, the $\mathrm{MoS}_{2}$ coated bolt has better anti-loosening performance than the PTFE coated bolt.

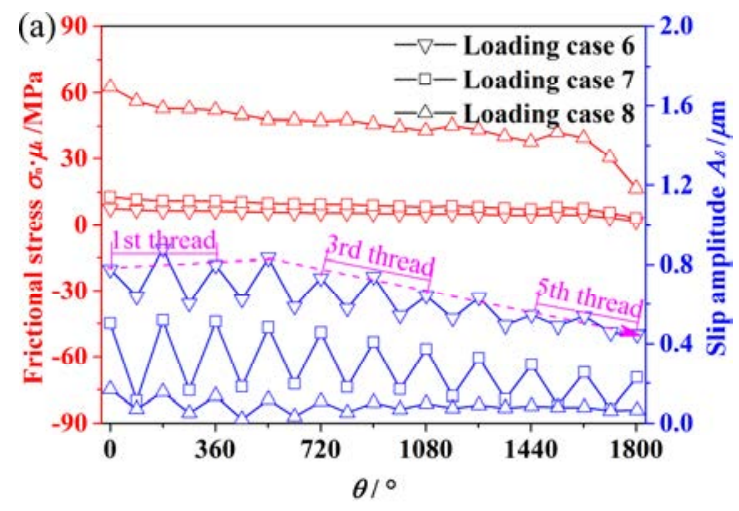

(a) Frictional stress at $t_{3}$ and displacement amplitude

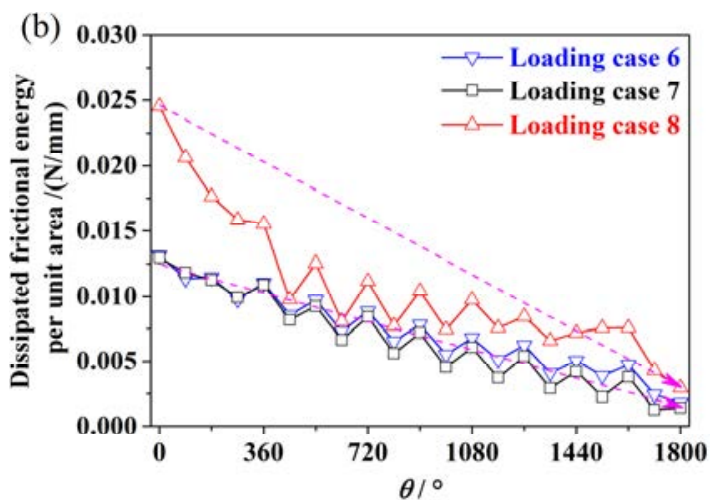

(b) Dissipated frictional energy

Fig. 38. Frictional stress at $t_{3}$, displacement amplitude and dissipated frictional energy along Path 2 for varying friction coefficients between the contact surfaces

\subsection{Preload selection}

According to the von Mises yield criterion, under the same equivalent stress as that of the uncoated bolt at the thread root, the preload for the $\mathrm{MoS}_{2}$ coated bolt increases by nearly 20\%. Fig. 39 shows the variations of clamping force, maximum cumulative plastic deformation at the thread roots and relative slippage at point $\mathrm{A}$ for different loading cases. Compared with the $\mathrm{MoS}_{2}$ coated bolt with the preload of $18 \mathrm{kN}$ (Loading case 7), maximum cumulative plastic deformation at the thread roots and relative slippage at point A become smaller when the preload is raised to $21.5 \mathrm{kN}$ (Loading case 9), and then the ratio of the residual axial load of the bolt to preload increases.

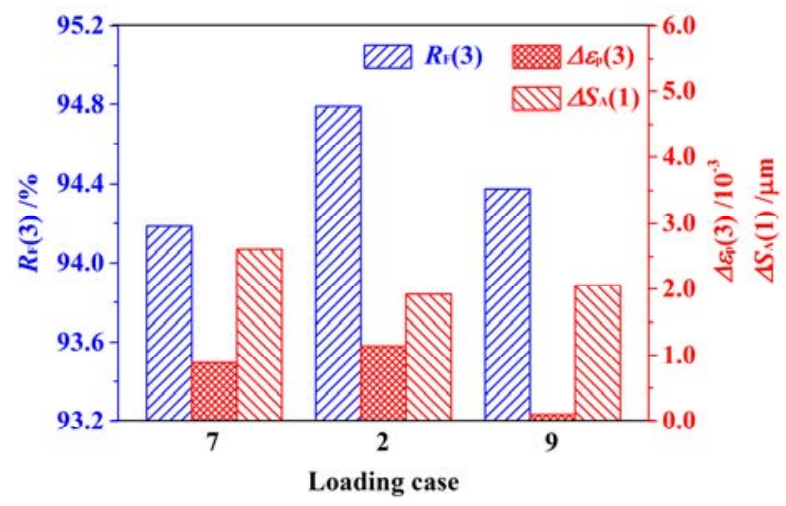

Fig. 39. Variations of clamping force, maximum cumulative plastic deformation at the thread roots and relative slippage at point $\mathrm{A}$ for different loading cases

Fig. 40 and Fig. 41 show the frictional stress at $t_{3}$, displacement amplitude and dissipated frictional energy (from $t_{2}$ to $t_{4}$ ) along Path 1 for different loading cases. For the $\mathrm{MoS}_{2}$ coated bolt 
with a preload of $21.5 \mathrm{kN}$, it is found that the displacement amplitude and the dissipated frictional energy are small. Equipped with good adhesion and self-lubrication of $\mathrm{MoS}_{2}$ coating, the damage of threads is slight. This suggests that the clamping force loss caused by fretting wear between the threads is small in practice. Because there are not many asperities on the threads, and then the clamping force loss caused by the plastic deformation, diminution in size, or removal of the asperities is also mild. Consequently, the anti-loosening performance can be greatly improved and the clamping force can be reduced as well by treating bolts with $\mathrm{MoS}_{2}$ coating.

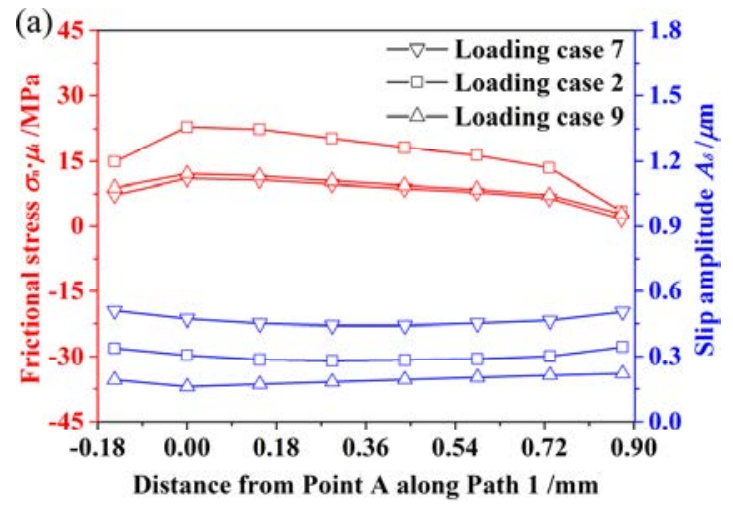

(a) Frictional stress at $t_{3}$ and displacement amplitude

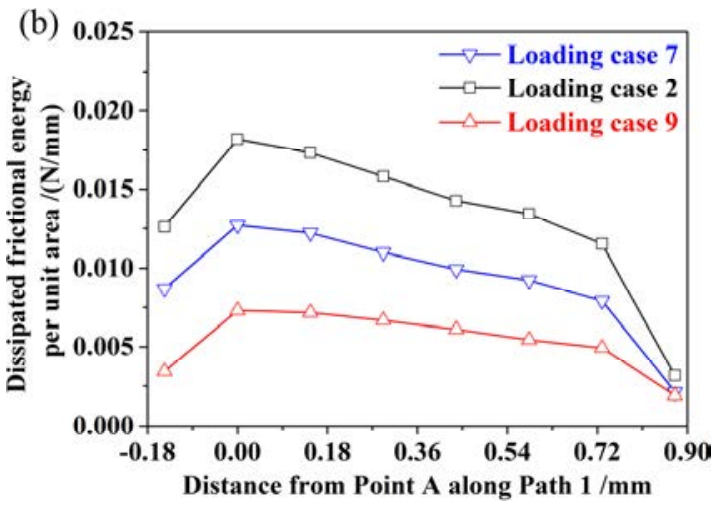

(b) Dissipated frictional energy

Fig. 40. Frictional stress at $t_{3}$, displacement amplitude and dissipated frictional energy along Path 1 for different loading cases

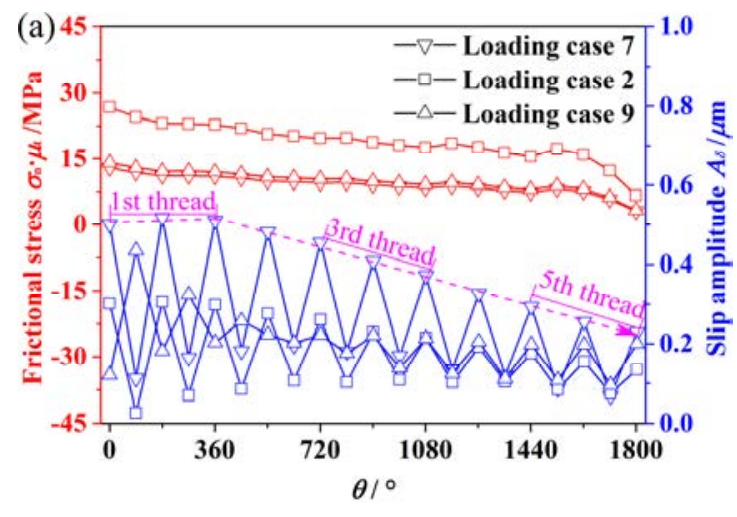

(a) Frictional stress at $t_{3}$ and displacement amplitude

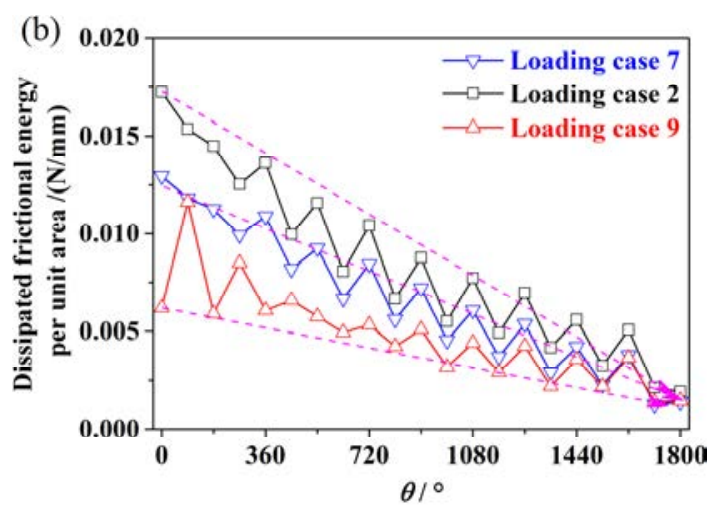

(b) Dissipated frictional energy

Fig. 41. Frictional stress at $t_{3}$, displacement amplitude and dissipated frictional energy along Path 2 for different loading cases

\section{Discussions}

According to previous studies, damage gets serious with the increase of the cumulative dissipated friction energy ${ }^{[69-71]}$.

Under high preload, the frictional stress on the contact threads is so large that the slip is not easy to occur and the cumulative dissipated friction energy is small under the same excitation amplitude (Figs. 31 and 32), suggesting that the thread damage is slight (Fig. 2). In fact, the contact on the microscopic scale occurs on the discontinuous surfaces of the asperity peaks. Plastic flattening of asperities at the contact areas, designated as "embedding", causes the clamp 
force to decrease ${ }^{[72]}$. Under high preload, most of the asperities on the thread surface are plastically flattened, or even removed, during the tightening process, and the real contact area is larger than that under low preload. Additionally, the change of the axial load to which the bolt shank is subjected decreases with the increasing preload (Fig. 28). Consequently, the plastic deformation/removal of the asperities on the contact surfaces caused by axial excitation is slight under high preload (Fig. 30). Therefore, the bolted joint is not prone to loosening under high preload because of the slight thread surface damage and the slight plastic deformation/removal of the asperities on the contact surfaces (Fig. 5).

Under high axial excitation amplitude, the component of the excitation on the thread surface, which leads to slip between the contact threads, is very large so that the slip is easy to occur. Coupled with the high frictional stress, the cumulative dissipated friction energy is also large under the same preload (Figs. 34 and 35), suggesting that the thread damage is serious (Figs. 2(b) and 6). Fig. 28 shows that the change of the axial load increases with the increasing axial excitation amplitude, and then the plastic deformation of the asperities on the contact surfaces increases (Fig. 33). Consequently, the bolted joint subjected to high axial excitation is easy to loosen because of the serious thread surface damage and the serious plastic deformation/removal of the asperities on the contact surfaces (Fig. 8).

For the PTFE/MoS 2 coated bolt, most of the asperities on the contact surfaces are plastically flattened/removed during the tightening process because of the low hardness of the coatings, and the real contact area is larger than that for the uncoated bolt, so the plastic deformation/removal of the asperities on the contact surfaces caused by the same axial excitation is slight. Consequently, the clamp force drops more slowly than that for the uncoated bolt in the early experiment period (Fig. 13(a)). Additionally, slip between the contact threads is easy to occur because of the low friction coefficient, and the slip amplitude is larger than that for the uncoated bolt. However, the frictional stress is small, and the cumulative dissipated friction energy is smaller than that for the uncoated bolt (Figs. 31(b) and 37(b)). It is important to note that the bonding strength between coating and bolt matrix is low for the PTFE coated bolt, so the PTFE coating is easy to be removed from the substrate under axial excitation (Fig. 10). Therefore, the clamp force drops quickly in the late experiment period (Fig. 13(a)). For the $\mathrm{MoS}_{2}$ coated bolt, abrasive wear, a slight form of wear, is the main wear mechanism because of the self-lubricating property of $\mathrm{MoS}_{2}$ particles produced by fretting wear. Coupled with the high bonding strength, the thread damage is slight (Fig. 11) and the clamp force drops slowly in the late experiment period (Fig. 13(a)).

For the TiN coated bolt, due to the excellent wear resistance and high bonding strength, the thread damage is slight, and the clamp force decreases slowly in the late experiment period (Fig. 13(a)). However, large tightening torque is required to apply the preload because of the high friction coefficient. It may cause the threads to undergo the plastic deformation (Fig. 9(c)), which is not permitted in practical engineering. Consequently, the TiN coating is not appropriate to apply to the fastener surface.

Because of the low friction coefficient between the contact threads for the $\mathrm{MoS}_{2}$ coated bolt, the shear stress on the thread surface is small, tightening torque can be properly enhanced to improve the bolt preload, together with the self-lubricating property and the high bonding strength, the thread surface damage is slight (Figs. 9(b) and 14) and the change in clamping force becomes small (Fig. 16(a)). So $\mathrm{MoS}_{2}$ is the best coating among the three. 


\section{Conclusions}

Self-loosening behaviour of bolted joints excited by dynamic axial load is investigated, and thread damage is analysed by OM, SEM and EDS. In addition, the anti-loosening performance of three types of coating on the bolts is examined. From the experimental results, the following conclusions can be drawn:

1. With the increasing preload and the decreasing excitation amplitude, the bolted joint is not prone to loosening because of the slight thread surface damage and the slight plastic deformation/removal of the asperities on the contact surfaces. Additionally, delamination is the main wear mechanism, and adhesive wear and abrasive wear also occur on the damaged thread.

2. In the first stage of loosening process (the first 100 cycles of excitation), for the PTFE/MoS ${ }_{2}$ coated bolts, a large number of asperities on the contact surfaces deform plastically, diminish in size, or are even removed during the tightening process due to the low hardness of the coating, the real contact area is large, and the plastic deformation/removal of the asperities on the contact surfaces caused by axial excitation is slight, then the change in clamping force is small. In contrast, the change in clamping force of the bolt coated with TiN is large in this stage.

3. In the second stage of loosening process (from the $10^{2}$ th cycle to the $10^{6}$ th cycle), due to the poor adhesion property of PTFE coating, the damage of the coating on threads is serious, and the change in clamping force of the PTFE coated bolts is large in this stage. For the $\mathrm{MoS}_{2}$ coated bolts, because of their good self-lubricating property and high bonding strength, the thread surface damage is slight and the change in clamping force is small in this stage. For the bolt coated with TiN, the damage of the coating on threads is slight due to its excellent wear resistance, and the change in clamping force is also small in this stage.

4. For the bolt coated with $\mathrm{MoS}_{2}$, the tightening torque is small because of the low friction coefficient. Therefore, under the same equivalent stress as that of the uncoated bolt at the thread root, the preload increases significantly, and the anti-loosening performance can be greatly improved.

5. The cumulative dissipated friction energy on thread surfaces increases with the decreasing preload and the increasing excitation amplitude. It becomes small for the $\mathrm{MoS}_{2}$ coated bolt under a sensible level of preload optimization. The numerical results are in agreement with the experimental observations.

\section{Acknowledgements}

The authors gratefully acknowledge the financial support provided by National Natural Science Foundation of China (No. U1534209), the Open Fund of State Key Laboratory of Traction Power (No. 2016TPL-Z03). 


\section{References}

1. J.N. Goodier, R.J. Sweeney. Loosening by vibration of threaded fastenings. Mechanical Engineering, 1945. 67: p. 794-800.

2. Y. Jiang, M. Zhang, T.W. Park, C.H. Lee. An experimental study of self-loosening of bolted joints. Journal of Mechanical Design, 2004. 126(5): p. 925-931.

3. X. Yang, S.A. Nassar, Z. Wu, A. Meng. Clamp load loss in a bolted joint model with plastic bolt elongation and eccentric service load. Proceedings of the ASME 2010 Pressure Vessels \& Piping Division/K-PVP Conference, Bellevue, Washington, USA, July 18-22, 2010.

4. J. Liu, H. Ouyang, J. Peng, C. Zhang, P. Zhou, L. Ma, M. Zhu. Experimental and numerical studies of bolted joints subjected to axial excitation. Wear, 2016. 346-347: p. 66-77.

5. S.A. Nassar, P.H. Mattin. Clamp load loss due to fastener elongation beyond its elastic limit. Journal of Pressure Vessel Technology, 2006. 128: p. 379-387.

6. B.A. Housari, S.A. Nassar. Effect of thread and bearing friction coefficients on the vibration-induced loosening of threaded fasteners. Journal of Vibration and Acoustics, 2007. 129(4): p. 484-494.

7. D.P. Hess, O.P. Keifer, C.B. Moody. Tests on loosening of aviation threaded fasteners with different washer configurations. Journal of Failure Analysis and Prevention, 2014. 14(5): p. 683-689.

8. A.M. Zaki, S.A. Nassar, X. Yang. Effect of thread and bearing friction coefficients on the self-loosening of preloaded countersunk-head bolts under periodic transverse excitation. Journal of Tribology, 2010. 132(3): p. 031601.

9. S. Hosokawa, S. Sato, C. Miyata, T. Tumura. Contraction deformation of bolt shank in threaded connection. Journal of the Japan Society for Precision Engineering, 1987. 53(11): p. 1726-1732.

10. G.H. Junker. New criteria for self-loosening faster under vibration. SAE, Transactions, 1969. 78: p. 314-335

11. T. Sakai. The friction coefficient of fasteners. Bulletin of Japanese Society of Mechanical Engineering, 1978. 21: p. 333-340.

12. O. Vinogradov, X. Haung. On a high frequency mechanism of self-loosening of fasteners. Proceedings of 12th ASME Conference on Mechanical Vibration and Noise, Montreal, Quebec, 1989: p. 131-137.

13. A. Daadbin, Y.M. Chow. Theoretical models to study thread loosening. Mechanism and Machine Theory, 1993. 27: p. 69-74.

14. J.H. Bickford. Introduction to the design and analysis of bolted joints, 4th ed. The Chemical Rubber Company Press, Florida, 2007.

15. M. Zhang, Y. Jiang, C.H. Lee. Finite element modeling of self-loosening of bolted joints. Journal of Mechanical Design, 2007. 129(2): p. 218-226.

16. Y. Jiang, M. Zhang, C.H. Lee. A study of early stage self-loosening of bolted joints. Journal of Mechanical Design, 2003. 125(3): p. 518-526.

17. R.A Ibrahim, C.L. Pettit. Uncertainties and dynamic problems of bolted joints and other fasteners. Journal of Sound and Vibration, 2005. 279(3-5): p. 857-936.

18. R.R. Schmitt, W.J. Horn. Viscoelastic relaxation in bolted thermoplastic composite joints. 
Proceedings of SAMPE Symposium and Exhibits, 1990. 35: p. 1336-1347.

19. W.J. Horn, R.R. Schmitt. Relaxation in bolted thermoplastic composite joints. AIAA/ASME/ASCE/AHS/ASCE Structures, Structural Dynamics, and Material Conference, Part 1, 1993. 485-494.

20. G.E. Ramey, R.C. Jenkins. Experimental analysis of thread movement in bolted connections due to vibrations. Final Report NAS8-39131, Marshall Space Flight Center, AL, 1995.

21. D.P. Hess, K. Davis. Threaded components under axial harmonic vibration, Part 1: Experiments. Journal of Vibration and Acoustics, 1996. 118(3): p. 417-422.

22. D.P. Hess. Threaded components under axial harmonic vibration, Part 2: Kinematic analysis. Journal of Vibration and Acoustics, 1996. 118(3): p. 423-429.

23. M. Leonavičius, A. Krenevičius. Shakedown and failure of the threaded joints under low cyclic loading. Journal of Construction Steel Research, 1998. 46: p. 452-453.

24. A.K. Graham, D.P. Hess, H.M. Stephens. Screw loosening in an in vitro mid fibular osteotomy model under dynamic loading conditions. Foot \& Ankle International, 2000. 21(10): p. 849-851.

25. S.A. Nassar, X. Yang, S.V.T. Gandham, Z. Wu. Nonlinear deformation behavior of clamped bolted joints under a separating service load. Journal of Pressure Vessel Technology, 2011. 133(2): p. 021001.

26. X. Yang, S.A. Nassar, Z. Wu, A. Meng. Nonlinear behavior of preloaded bolted joints under a cyclic separating load. Journal of Pressure Vessel Technology, 2012. 134(1): p. 011206.

27. H. Bahai, I.I. Esat. A hybrid model for analysis of complex stress distribution in threaded connectors. Computers \& Structures, 1994. 52(1): p. 79-93.

28. H. Zhao. Stress concentration factors within bolt-nut connectors under elasto-plastic deformation. International Journal of Fatigue, 1998. 20(9): p. 651-659.

29. F. Alkatan, P. Stephan, A. Daidie, J. Guillot. Equivalent axial stiffness of various components in bolted joints subjected to axial loading. Finite Elements in Analysis and Design, 2007. 43(8): p. 589-598.

30. J. Liu, H. Ouyang, L. Ma, C. Zhang, M. Zhu. Numerical and theoretical studies of bolted joints under harmonic shear displacement. Latin American Journal of Solids and Structures, 2015. 12(1): p. 115-132.

31. S. Izumi, T. Yokoyama, A. Iwasaki, S. Sakai. Three-dimensional finite element analysis of tightening and loosening mechanism of threaded fastener. Engineering Failure Analysis, 2005. 12(4): p. 604-615.

32. S. Izumi, T. Yokoyama, M. Kimura, S. Sakai. Loosening-resistance evaluation of double-nut tightening method and spring washer by three-dimensional finite element analysis. Engineering Failure Analysis, 2009. 16(5): p. 1510-1519.

33. T. Yokoyama, M. Olsson, S. Izumi, S. Sakai. Investigation into the self-loosening behavior of bolted joint subjected to rotational loading. Engineering Failure Analysis, 2012. 23: p. 35-43.

34. M. Ishimura, T. Sawa, A. Karami, T. Nagao. Bolt-nut loosening in bolted flange connections under repeated bending moments. ASME 2010 Pressure Vessels and Piping Conference, Bellevue, Washington, USA, 2010.

35. G. Dinger, C. Friedrich. Avoiding self-loosening failure of bolted joints with numerical assessment of local contact state. Engineering Failure Analysis, 2011. 18(8): p. 2188-2200.

36. T. Fukuoka, M. Nomura. Proposition of helical thread modeling with accurate geometry and finite element analysis. Journal of Pressure Vessel Technology, 2008. 130(1): p. 011204.

37. G. Yang, J. Hong, L. Zhu, B. Li, M. Xiong, F. Wang. Three-dimensional finite element 
analysis of the mechanical properties of helical thread connection. Chinese Journal of Mechanical Engineering, 2013. 26(3): p. 564-572.

38. R.M. Rafatpanah. Finite element analysis of a three-dimensional threaded structural fastener. [D]. Rensselaer Polytechnic Institute, Hartford, USA, 2013.

39. Z. Qin, D. Cui, S. Yan, F. Chu. Hysteresis modeling of clamp band joint with macro-slip. Mechanical Systems and Signal Processing, 2016. 66-67: p. 89-110.

40. Z. Qin, D. Cui, S. Yan, F. Chu. Application of 2D finite element model for nonlinear dynamic analysis of clamp band joint. Journal of Vibration and Control, 2015.

41 M. Oldfield, H. Ouyang, J.E. Mottershead. Simplified models of bolted joints under harmonic loading. Computers \& Structures, 2005. 84(1-2): p. 25-33.

42. J. Abad, F.J. Medel, J.M. Franco. Determination of Valanis model parameters in a bolted lap joint: experimental and numerical analyses of frictional dissipation. International Journal of Mechanical Sciences, 2014. 89: p. 289-298.

43. Y. Karim, C. Blanzé. Vibration reduction of a structure by design and control of a bolted joint. Computers \& Structures, 2014. 138: p. 73-85.

44. Y. Shi, Y. Zhou. ABAQUS finite element analysis of detailed examples. 1st ed. China machine press, Beijing, 2006.

45. N.G. Pai, D.P.H., Three-dimensional finite element analysis of threaded fastener loosening due to dynamic shear load. Engineering Failure Analysis, 2002. 9: p. 383-402.

46. W. Eccles. Bolted joint design. Engineering Design 10, 1984: p. 10-14.

47. N. Sase, S. Koga, K. Nishioka, H. Fujii. Evaluation of anti-loosening nuts for screw fasteners. Journal of Materials Processing Technology, 1996. 56(1-4): p. 321-332.

48. T. Sawa, M. Ishimura, H. Yamanaka. Experimental evaluation of screw thread loosening in bolted joint with some parts for preventing the loosening under transverse repeated loadings. ASME, Pressure Vessels and Piping, 2006. 2: p. 211-220.

49. A. Bhattacharya, A. Sen, S. Das. An investigation on the anti-loosening characteristics of threaded fasteners under vibratory conditions. Mechanism and Machine Theory, 2010. 45(8): p. 1215-1225.

50. C.A. Cheatham, C.F. Acosta, D.P. Hess. Tests and analysis of secondary locking features in threaded inserts. Engineering Failure Analysis, 2009. 16(1): p. 39-57.

51. T. Takemasu, H. Miyahara. Development of thread rolled anti-loosening bolts based on the double thread mechanism and a performance evaluation. JSME/ASME International Conference on Materials and Processing, 2005. 48(4): p. 305-310.

52. W. Eccles, I. Sherrington, R.D. Arnell. Towards an understanding of the loosening characteristics of prevailing torque nuts. Proceedings of the Institution of Mechanical Engineers, Part C: Journal of Mechanical Engineering Science, 2010. 224(2): p. 483-495.

53. N. Sase, K. Nishioka, S. Koga, H. Fujii. An anti-loosening screw fastener innovation and its evaluation. Journal of Materials Processing Technology, 1998. 77(1-3): p. 209-215.

54. N. Sase, H. Fujii. Optimizing study of SLBs for higher anti-loosening performance. Journal of Materials Processing Technology, 2001. 119(1-3): p. 174-179.

55. S. Beckford, L. Mathurin, J. Chen, R.A. Fleming, M. Zou. The effects of polydopamine coated $\mathrm{Cu}$ nanoparticles on the tribological properties of polydopamine/PTFE coatings. Tribology International, 2016. 103: p. 87-94.

56. S. Beckford, M. Zou. Wear resistant PTFE thin film enabled by a polydopamine adhesive layer. Applied Surface Science, 2014. 292: p. 350-356.

57. M. Ye, G. Zhang, Y. Ba, T. Wang, X. Wang, Z. Liu, Microstructure and tribological properties 
of $\mathrm{MoS}_{2}+\mathrm{Zr}$ composite coatings in high humidity environment. Applied Surface Science, 2016. 367: p. 140-146.

58. K. Hu, Y. Xu, E. Hu, J. Guo, X. Hu. Rolling friction performance and functional conversion from lubrication to photocatalysis of hollow spherical nano-MoS2/nano-TiO2. Tribology International, 2016. 104: p. 131-139.

59. J.J. Nainaparampil, A.R. Phani, J.E. Krzanowski, J.S. Zabinski. Pulsed laser-ablated $\mathrm{MoS}_{2}-\mathrm{Al}$ films: friction and wear in humid conditions. Surface and Coatings Technology, 2004. 187(2-3): p. 326-335.

60. T. Aiso, U. Wiklund, M. Kubota, S. Jacobson. Influence of $\mathrm{Mn}$ and $\mathrm{Al}$ additions to carbon steel on material transfer and coating damage mechanism in a sliding contact between steel and TiN coated HSS tool. Tribology International, 2016. 101: p. 414-424.

61. N. Lin, X. Huang, X. Zhang, A. Fan, L. Qin, B. Tang. In vitro assessments on bacterial adhesion and corrosion performance of TiN coating on Ti6Al4V titanium alloy synthesized by multi-arc ion plating. Applied Surface Science, 2012. 258(18): p. 7047-7051.

62. V. Jayaram, S. Bhowmick, Z.H. Xie, S. Math, M. Hoffman, S.K. Biswas. Contact deformation of TiN coatings on metallic substrates. Materials Science and Engineering: A, 2006. 423(1-2): p. 8-13.

63. G. Ma, L. Wang, H. Gao, J. Zhang, T. Reddyhoff. The friction coefficient evolution of a TiN coated contact during sliding wear. Applied Surface Science, 2015. 345: p. 109-115.

64. D. Cheng. Handbook of mechanical design, 4th ed. Chemical Industry Press, Beijing, 2010.

65. T. Yokoyama, M. Olsson, S. Izumi, S. Sakai. Investigation into the self-loosening behavior of bolted joint subjected to rotational loading. Engineering Failure Analysis, 2012. 23: p. 35-43.

66. J. Liu. Research on the self-loosening mechanism of bolted joints under axial excitation. Ph.D. Thesis. Southwest Jiaotong University, China, 2016.

67. T. Yamamoto. The theory and computation of threads connection. Tokyo: Yokendo. 1980.

68. Y. Fujioka, T. Sakai. Rotating loosening mechanism of a nut connecting a rotary disk under rotating-bending force. Journal of Mechanical Design, 2005. 127(6): p. 1191-1197.

69. V. Fridrici, S. Fouvry, Ph. Kapsa. Effect of shot peening on the fretting wear of Ti-6Al-4V. Wear, 2001. 250: p. 642-649.

70. Z. Zhou, M. Zhu. Composite Fretting Wear, 1st ed. Shanghai Jiao Tong University Press, Shanghai, 2004.

71. Z. Cai, M. Zhu, S. Yang, X. Xiao, X. Liu. H. Yu. In situ observations of the real-time wear of PMMA flat against steel ball under torsional fretting. Wear, 2011. 271: 2242-2251

72. The Association of German Engineers(VDI). Systematic calculation of high duty bolted joints. German, 2014 